$15^{\text {th }}$ International Conference on

AEROSPACE SCIENCES \& AVIATION TECHNOLOGY,

ASAT - 15 - May 28 - 30, 2013, Email: asat@mtc.edu.eg,

Military Technical College, Kobry Elkobbah, Cairo, Egypt,

Tel: +(202) $24025292-24036138$, Fax: +(202) 22621908

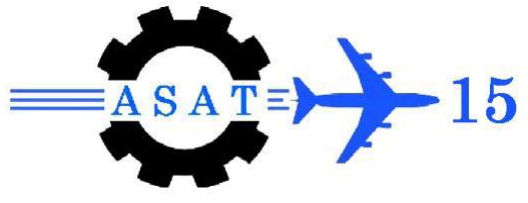

\title{
Ballistic Analysis of a Projectile Provided with Base Bleed Unit
}

\author{
$\left\{\right.$ H.A. Abou-Elela, A.Z. Ibrahim, O.K. Mahmoud and O.E. Abdel-Hamid ${ }^{*}$
}

\begin{abstract}
An analysis has been performed to investigate the ballistic performance of the $155 \mathrm{~mm}$ K307 extended range projectile provided with base bleed unit. Different tools were used to perform this analysis; including analytical modeling and available computational resources. Drag reduction modeling has been used to study the effect of different parameters on base bleed performance such as burning rate, number of base bleed grain parts and the grain dimensions. The study has showed that a better ballistic performance could be obtained when the exit mass flow rate of the burnt gases is relatively large at the first few seconds of the projectile flight. To change this mass flow rate along the trajectory, a newly developed technique has been introduced. The technique depends on filling the base bleed unit with a grain subjected to burning by two rates resulting in extending the projectile range.
\end{abstract}

Keywords: Aerodynamics, CFD, base bleed, injection parameter, extended range, drag reduction.

\section{Nomenclature}

$\mathrm{Ab} \quad$ Projectile base area.

AJ Base bleed ejection area.

$\mathrm{Db} \quad$ Projectile base diameter

$\mathrm{I}_{\mathrm{X}} \quad$ Initial axial moment of inertia of projectile at certain time increment $\mathrm{i}$

$\mathrm{I}_{\mathrm{Xo}} \quad$ Initial axial moment of inertia of projectile

$\mathrm{I}_{\mathrm{Xb}} \quad$ Axial moment of inertia of projectile after burn out base bleed

$\mathrm{K} \quad$ Specific heat ratio of base bleed ejected.

$K_{\infty} \quad$ Specific heat ratio of air.

$k_{r} \quad$ Parameter of spin rate effect on base bleed inner radius.

$k_{\omega} \quad$ Parameter of spin rate effect on base bleed slots.

$\mathrm{L}_{\mathrm{i}} \quad$ Maximum base bleed grain length.

M Free stream Mach number

$m_{0} \quad$ Initial projectile mass.

$m_{b} \quad$ Projectile mass after burnout of base bleed.

$\mathrm{N} \quad$ Number of base bleed grain parts.

$r_{i} \quad$ The inner radius of base bleed grain.

$r_{m x} \quad$ Maximum radius of base bleed grain.

$r_{s} \quad$ The radius of curved ends of base bleed grain.

$T_{G} \quad$ Temperature of base bleed ejected gases.

$t_{b b} \quad$ Burn time of base bleed grain.

\footnotetext{
* Egyptian Armed Forces, Egypt.
} 
$U_{r} \quad$ Regression rate of base bleed grain cylindrical radius.

$U_{\omega} \quad$ Regression rate of base bleed grain slots.

$P_{\infty} \quad$ Free stream pressure.

Vo $\quad$ Free stream velocity.

$\mathrm{y}+\quad$ Wall $\mathrm{y}+$ function.

$\rho_{G} \quad$ Base bleed propellant grain density.

$\rho \infty \quad$ Free stream air density.

$\Delta t \quad$ Time step of calculation.

$\omega_{\mathrm{i}} \quad$ Initial half thickness of base bleed grain slot.

$\Gamma \quad$ Air gas constant.

\section{Introduction}

Long range is an essential requirement for the developers of new ammunition. Base drag reduction is almost of main concern in order to increase the range since it represents more than $50 \%$ of the total drag affecting the projectile at transonic and supersonic speeds [1]. Base bleeding is an effective means to decrease the base drag via injecting hot burnt gases behind the projectile base. These gases raise the wake region pressure resulting in base drag reduction. The wake pressure depends mainly on a dimensionless variable called injection parameter (I) which is defined according to the following equation:

$$
\mathrm{I}=\frac{\dot{\mathrm{m}}_{\mathrm{N}}}{\dot{\mathrm{m}}_{\infty}}
$$

where, $\dot{m}_{N}$ is the mass flow rate of burnt gases through the nozzle exit and $\dot{m}_{\infty}$ is the upstream mass flow rate of air past the projectile base which can be determined using the following equation:

$$
\dot{\mathrm{m}}_{\infty}=\rho_{\infty} \mathrm{V}_{\infty} \mathrm{A}_{\mathrm{b}}
$$

The mass flow rate $\left(\dot{m}_{N}\right)$ is a function of the burning rate of base bleed grain composition and the exposed instantaneous grain surface $\left(\mathrm{A}_{\mathrm{bb}}\right)$.

$$
\mathrm{m}_{\mathrm{N}}=\mathrm{U} \mathrm{A}_{\mathrm{bb}} \rho_{\mathrm{bb}},
$$

where $\rho_{\mathrm{bb}}$ is the density of the grain composition and $\mathrm{U}$ is the grain burning rate which can be calculated according to the following equation $[6,11]$ :

$$
\mathrm{U}=\mathrm{k} \mathrm{U}_{0} \mathrm{P}_{\mathrm{ch}}^{\alpha} \text {, }
$$

where $\mathrm{k}$ is the spin rate factor, Uo is the grain burning rate at atmospheric pressure, Pch is the pressure of the base bleed unit chamber and $\alpha$ is the pressure exponent.

Projectile base configuration and the shape of base bleed orifice are of great influence on the base bleed performance since they affect the interaction between the ejected gases and free stream of air past the projectile base. These parameters have been numerically studied using the Computational Fluid Dynamics (CFD) capabilities [2] as well as the experimental work facilities including firing tests, wind tunnel testing and ground laboratory testing [3, 4].

Nils E. Gurnners [5], introduced a base bleed drag reduction model to calculate the trajectory and performance of base bleed projectile taking into consideration the effect of projectile spin. Drag reduction was calculated using semi empirical formula which is a function of the Mach number and injection parameter that was derived from wind tunnel testing. A good agreement has been demonstrated between predicted and experimental results. 
A study has been carried out to show the effect of burning rate of base bleed grain at values ranging from 0.8 to $2.2 \mathrm{~mm} / \mathrm{s}$ on the drag reduction coefficient [6]. The results have revealed that the higher is the burn rate; the higher is the drag reduction coefficient.

The experimental study of J. Danberg, et. al. [3, 7] has addressed the effect of spinning rate on the burning rate of the solid propellant as well as the effect of injection on the drag reduction. The study has been applied to M864 base bleed projectile. Ground spin apparatus has been exploited at different spin rates as well as different base bleed grains at specified base pressure to put a formula determining the burning rate equation. The results have been used to put an equation expressing the effect of spin on burn rate of base bleed grain surfaces (cylindrical and slots) in trajectory model.

Many researchers have investigated the effect of injection parameter on drag reduction for different Mach regions when ejecting air or other gases such as hydrogen or mixture of hot or cold gases [8, 9, and 10]. They have performed wind tunnel experimental work and CFD simulations to study the influence of injection parameter on the drag reduction. Their studies have revealed that drag reduction increases with the increase of injection parameter up to a certain optimum value depending on the type of ejected gases, ejection configuration and free stream conditions.

Jun-Silk Hwang, et al. [11] has introduced a model to predict drag reduction of base bleed projectiles flying at velocities ranging from 810 to $910 \mathrm{~m} / \mathrm{s}$. The augmentation of the burning rate due to projectile spinning has been included. The results have showed that the optimum burning rate corresponds to the maximum projectile range, ranges from 1.1 to $1.3 \mathrm{~mm} / \mathrm{s}$.

An experimental firing has been performed in order to enhance the base bleed projectile performance [12]. Three issues have been addressed in this study :i) the area of the burnt surface of the base bleed grain by changing the number of slots of the base bleed grain as it can be seen in Fig.1, ii) the burning rate of base bleed grain composition and iii) optimization of the base geometry. The study has resulted in better performance of projectile provided with base bleed unit having a grain of three slots.

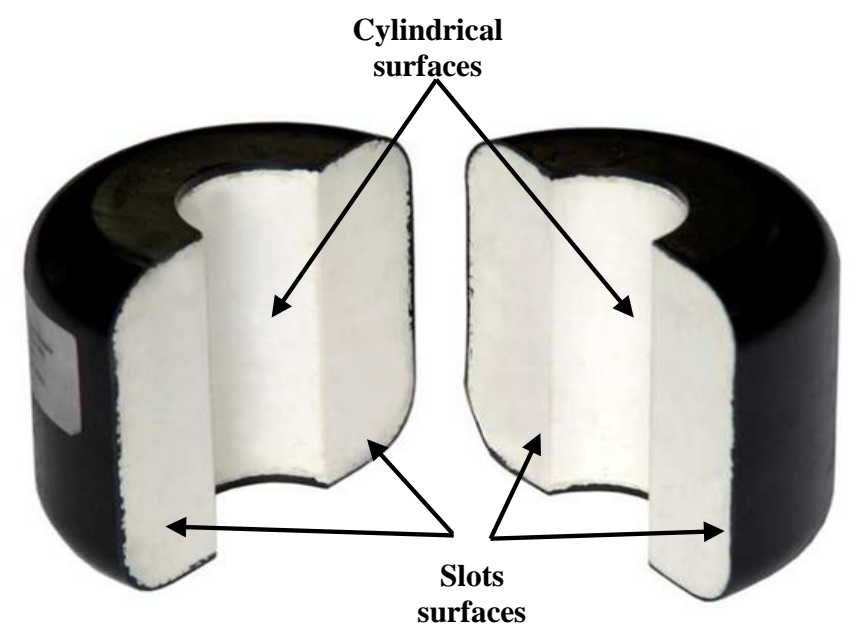

Fig. 1 Base bleed grain surfaces in case of 2-slot grain

Z. Ling-Ke, et al. [13] used the semi empirical formula used in [8] to study the ballistic performance of a $155 \mathrm{~mm}$ projectile with base bleed unit. In this study, a correction factor has been introduced as a multiplier to the formula to achieve best fit of model drag prediction with experimental data. 
N. Hubberud et al. [2] carried out a numerical study to simulate gas flow exit from base bleed unit at different injecting parameter values assuming the flow rate of air. They have predicted drag reduction factor as function of Mach number and injection parameter. Published results at Mach number of 1.6 have showed a good agreement with firing data except for the period just after muzzle and at transonic velocities.

Hereinafter, a semi-analytical model has been developed using a code written in C++ to predict the trajectory parameters of the base bleed projectile K307 [11]. The model was used to study the effect of changing the burning rate and grain geometry on the range resulting in a new technique to get a proper mass flow along the trajectory.

\section{Computational Work}

The computational work in this study was carried out on the projectile K307 [11] by applying RANS equations in steady state form using a commercial code. The relative dimensions in terms of projectile caliber, D are shown in Fig. 2. The implicit density base scheme was used to solve the system of differential equations. The second-order upwind Green-Gauss node based scheme was used in discretizing the spatial dependent properties in RANS equations [14].

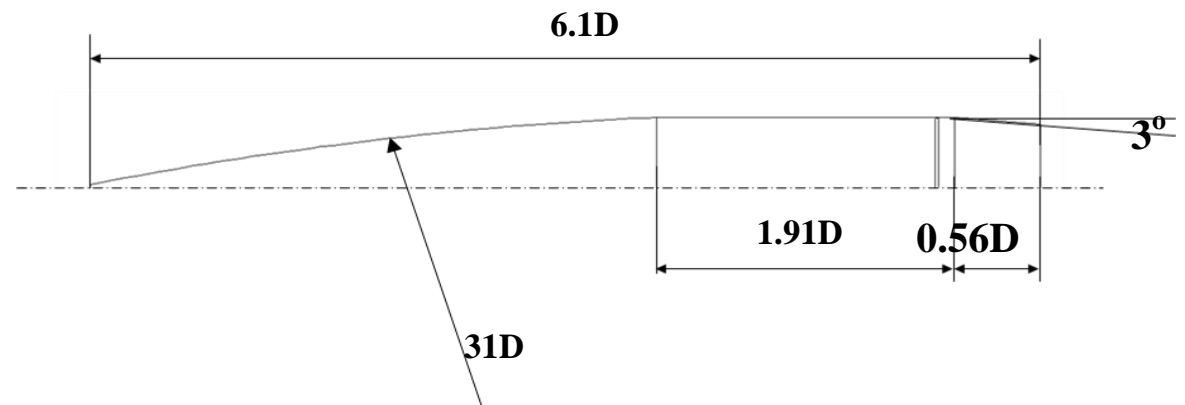

Fig. 2 Relative dimensions of the projectile model.

\section{Grid Generation}

Because of the symmetry of the computational domain around the conventional projectile, it is enough to generate the structured quadrilateral $\mathrm{C}$-grid in half of the domain as shown in Fig.3 [14]. The computational domain was divided into ten sectors. The division was useful to get smoothness of the grid and proper clustering of the cells near the critical segments of the projectile, where large gradients of the flow properties are expected.

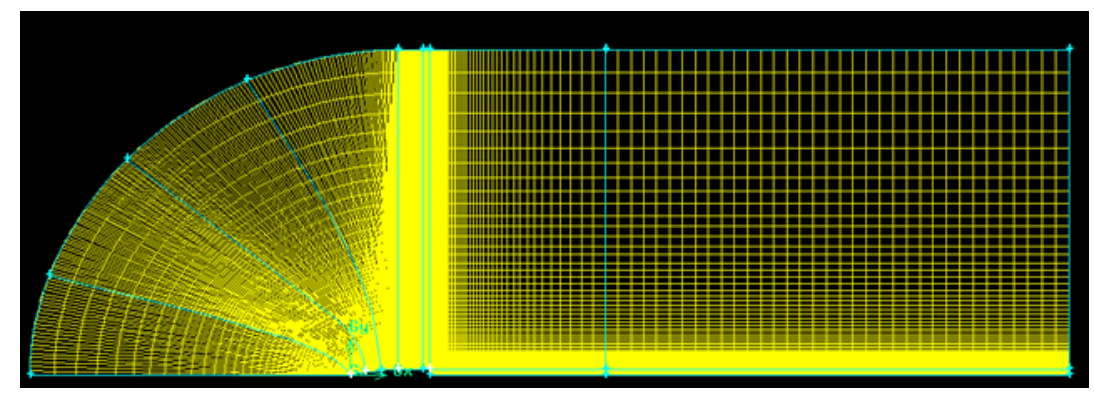

Fig. 3 The structured 2-D mesh

The height of the cells adjacent to the wall was adjusted such that, the value of the wall function $y+$ is less than 3 at the largest Mach number [14] . A 2-D axisymmetric mesh was originally generated for supersonic calculations [15] where the domain was extended in 
upstream and around projectile up to 25D (4L) in all directions except in the downstream; it was extended up to 50D (8L). According to [16] grid sensitivity study was carried out at the highest Mach number 2.68. Five structured 2-D grids have been generated using Gambit 2.4 to obtain the grid independent solution. The coarsest grid consists of 64640 cells and the size of the finest one is 114140 cells. The grid of 96180 cells was chosen for the present work with 356 points in the axial direction on projectile surface and 100 points in the lateral direction from the axis to projectile base corner and 140 points up to the domain. For transonic velocities, this grid was extended up to 37D (6L) in all directions except in the back of projectile; it was extended up to $62 \mathrm{D}(8 \mathrm{~L})$ keeping the entire stretching ratio less than 1.1 in both axial and lateral directions.

\section{Boundary Conditions}

The pressure far-field boundary was set to the uniform upstream flow. The symmetric boundary was applied to the line coincident with the projectile axis. The adiabatic no slip condition was set to the solid projectile surfaces.

\section{Results}

First, the numerical simulations were carried out at zero angle of attack for the inert projectile. The solution was initialized from the conditions at the far field boundary. Several turbulence models were applied (Spalart-Allmaras, k-omega SST, k-epsilon, k-epsilon-RNG, k-epsilonRealizable, Transition k-kl-omega). Total drag coefficient CDo was monitored as a criterion of convergence beside residuals. The solution is converged when the flow residuals are reduced at least three orders of magnitude [17] and CDo changed less than about $0.5 \%$ over the last 1000 iterations.

Comparing the calculated total drag coefficient using different turbulence models with the measured data of inert projectile [11], it was found that the results corresponding k-omega SST provided the best results as shown in Fig. 4. The maximum absolute error was $16 \%$ at Mach number 0.98. The large error is due to the drag divergence at the critical value of Mach number 0.98. However the absolute values of the predicted errors at Mach numbers larger than 0.98 are approximately less than $3 \%$. So k-omega SST turbulence model has been used in the current work.

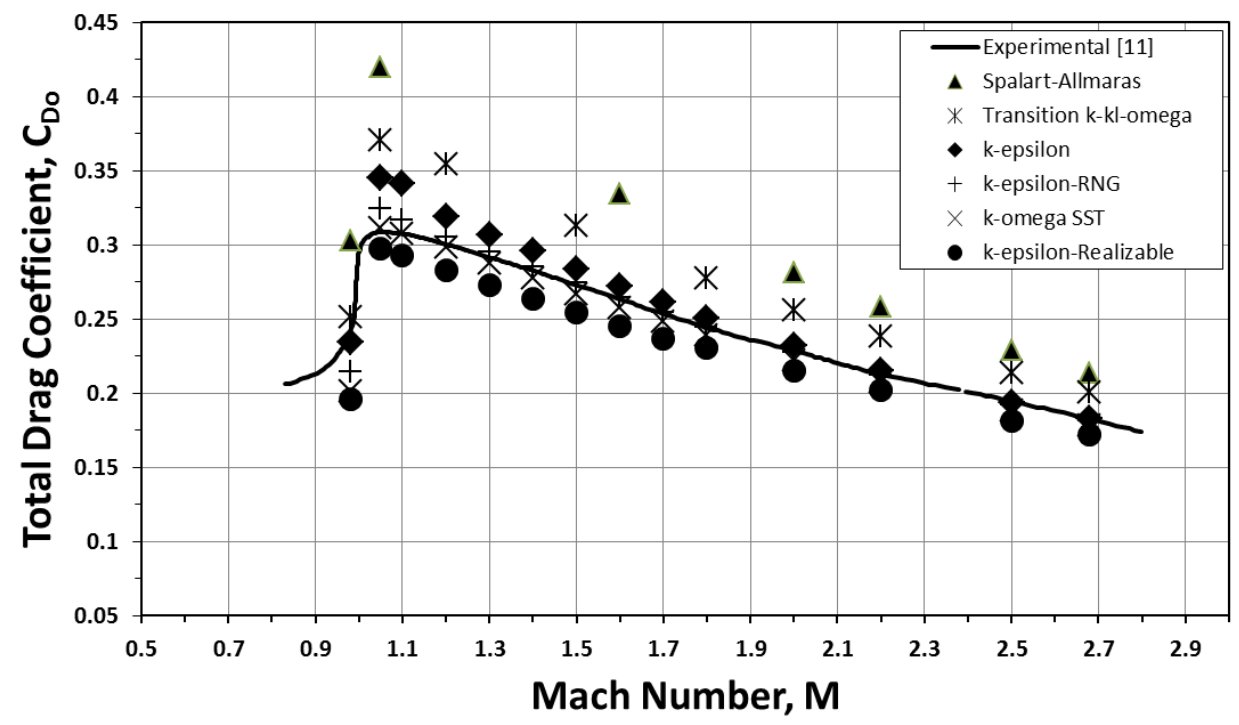

Fig. 4 Calculated total drag coefficient CDo versus Mach number for different turbulence models compared with the experimental results [11] 


\section{Trajectory Model}

A C++ code has been written in order to find out the trajectory parameters of a conventional projectile provided with a base bleed unit whenever it is switched on or off. A 2-D point mass model was used to calculate the trajectory parameters assuming that there is no angle of attack as shown in Fig.5.

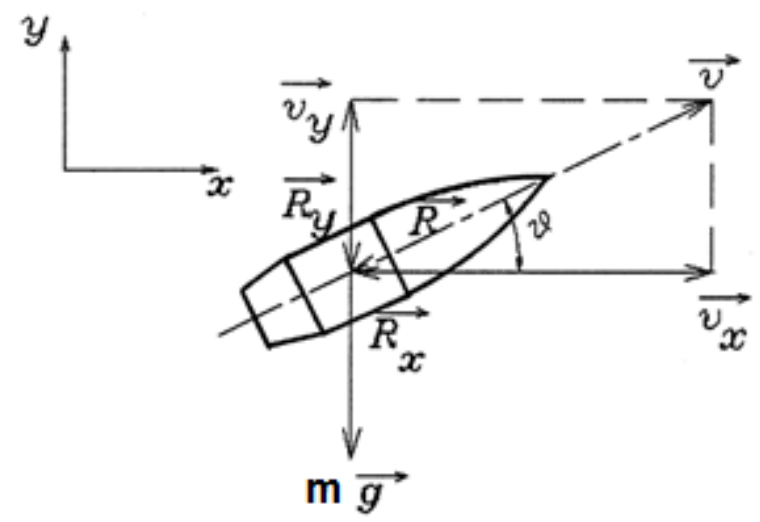

Fig. 5 Forces affecting the projectile during its flight in air

Therefore, the equations of projectile motion in $\mathrm{x}-\mathrm{y}$ plane are:

$\mathrm{m} \frac{\mathrm{dv_{ \textrm {x } }}}{\mathrm{dt}}=-\mathrm{R} \cos \theta$,

$\mathrm{m} \frac{\mathrm{dv} \mathrm{y}}{\mathrm{dt}}=-\mathrm{R} \sin \theta-\mathrm{mg}$,

where $\mathrm{v}_{\mathrm{x}}$ and $\mathrm{v}_{\mathrm{y}}$ are the components of projectile velocity in both $\mathrm{x}$ and $\mathrm{y}$ directions, respectively, $\mathrm{m}$ is the projectile mass, $\mathrm{R}$ is the air resistance, $\theta$ is the angle of elevation and $\mathrm{g}$ is the gravitational acceleration. The air resistance force is given by the following equation:

$$
\mathrm{R}=\frac{1}{2} \rho_{\infty} \mathrm{v}^{2} \mathrm{~S} \mathrm{C}_{\mathrm{D}_{0}}(\mathrm{M})
$$

where the upstream air density $\rho \infty$ changes with the projectile altitude according to the following equations [18]:

$$
\begin{array}{ll}
\rho_{\infty}=1.225\left(1-0.0065 \frac{\mathrm{y}}{\mathrm{T}_{\mathrm{o}}}\right)^{4.256}, & (0 \leq \mathrm{y} \leq 11000 \mathrm{~m}) \\
\rho_{\infty}=\rho_{11000} \mathrm{e}^{1.57(11000-\mathrm{y}) 10^{-4}}, & (\mathrm{y}>11000 \mathrm{~m})
\end{array}
$$

where $y$ is the projectile height, To is the air temperature at sea level, and $\rho 11000$ is the air density at $11000 \mathrm{~m}$ height. The differential equations of the projectile velocity in both $\mathrm{x}$ and $\mathrm{y}$ directions are:

$$
\begin{aligned}
& \mathrm{v}_{\mathrm{x}}=\frac{\mathrm{dx}}{\mathrm{dt}} \\
& \mathrm{v}_{\mathrm{y}}=\frac{\mathrm{dy}}{\mathrm{dt}}
\end{aligned}
$$

The system of the differential equations 5, 6, 10, and 11 can be solved numerically but CDo (M) must be determined first. Available CFD facilities were exploited in order to predict the value of CDo versus Mach number which is calculated as follows:

$\mathrm{M}=\frac{\mathrm{v}}{\sqrt{\gamma \mathrm{RT}}}$

The following equation relates air temperature to projectile altitude [18]: 


$$
\begin{array}{lc}
\mathrm{T}=\mathrm{T}_{\mathrm{o}}-0.0065 \mathrm{y}[\mathrm{K}] & (0 \leq \mathrm{y} \leq 11000 \mathrm{~m}) \\
\mathrm{T}=217[\mathrm{~K}] & (\mathrm{y}>11000 \mathrm{~m})
\end{array}
$$

The spin rate change during projectile flight was expressed by [19]:

$\frac{\mathrm{dSr}}{\mathrm{dt}}=\left(0.5 \mathrm{C}_{\mathrm{lp}} \rho_{\infty} \mathrm{vSD}{ }^{2} *\left(\frac{\mathrm{Sr}}{\mathrm{I}_{\mathrm{X}}}\right) * \Delta \mathrm{t}\right.$

Initial spin rate in case of constant rifling will be calculated by $\operatorname{Sr}_{0}=\frac{\mathrm{v}_{0}}{\eta}$ where $\eta$ is barrel rifle length for one turn, Clp is spin damping coefficient and $\mathrm{S}$ is the cross section area of projectile.

Figure 6 displays the predicted trajectories at different muzzle velocity compared with their counterparts published in [3]. A good agreement can be noted since the maximum error in range is less than $1.4 \%$.

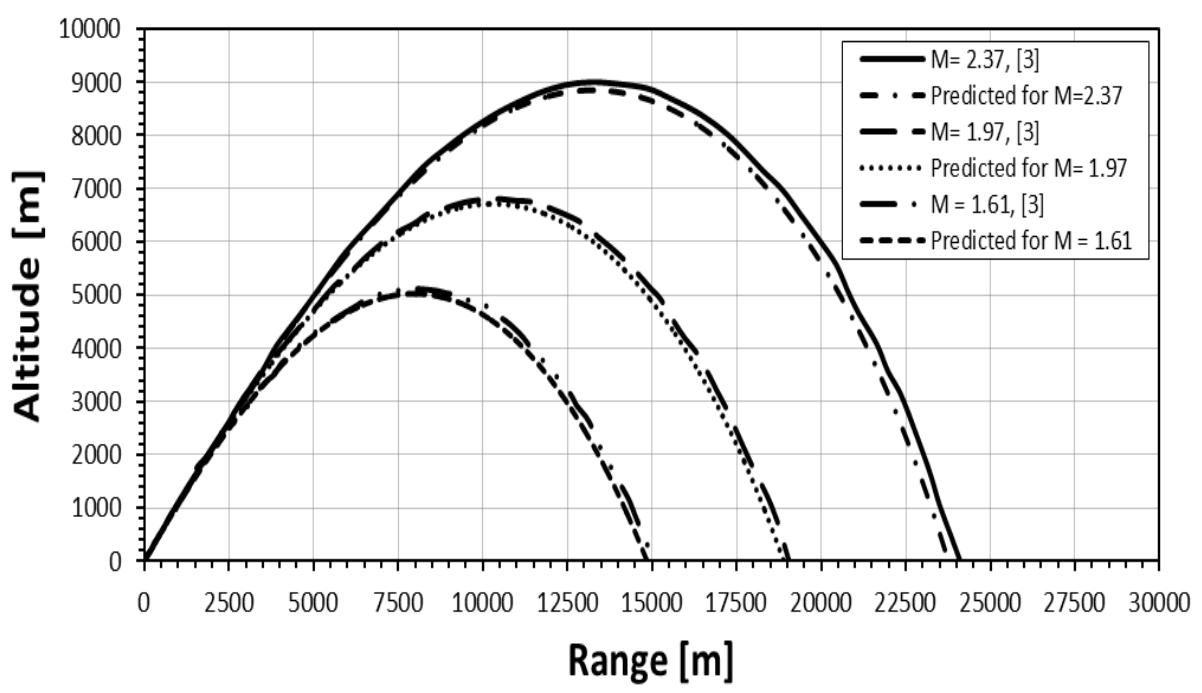

Fig. 6 Predicted trajectories at different muzzle velocities compared with the measured ones [3]

The predicted spin rate with time of flight is compared with the measured one for the aforementioned trajectories in Fig. 7 and good agreement can be noted in all trajectories.

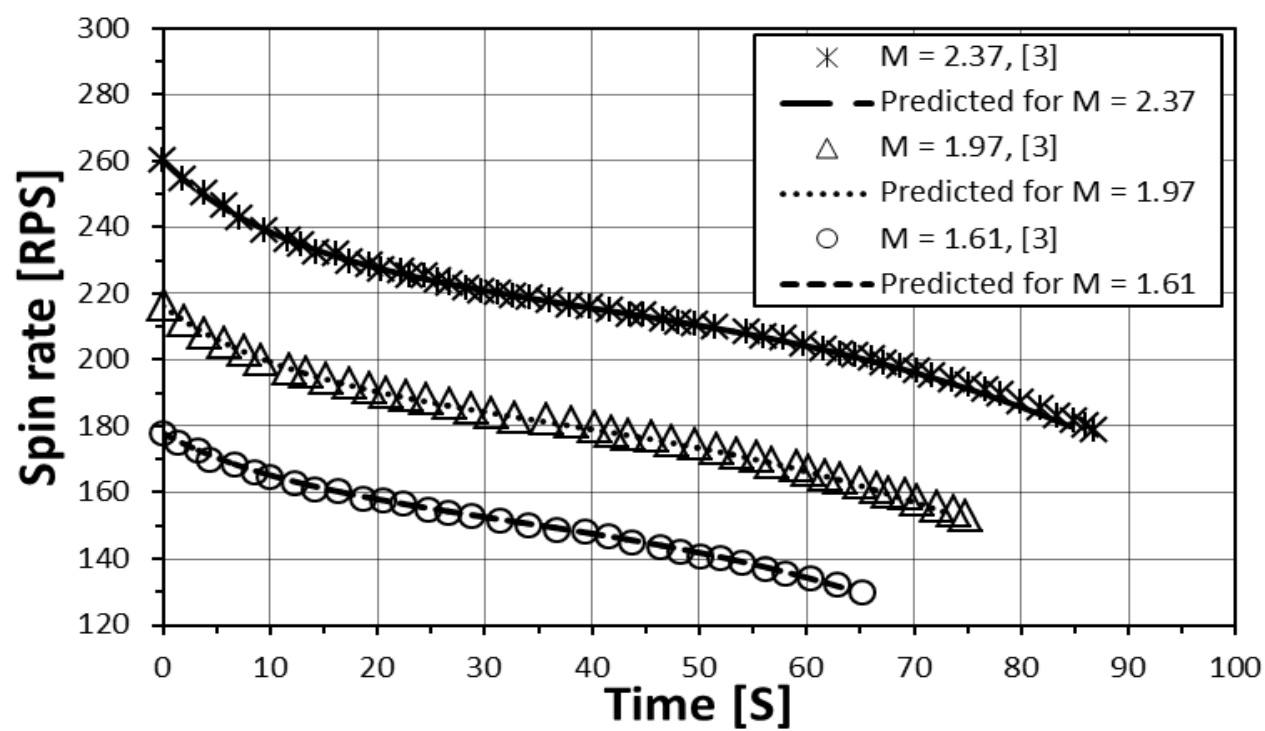

Fig. 7 Predicted spin rates at different muzzle velocities compared with the measured ones [3] 
For the current study, the coefficient Clp of the projectile K307 [shown in Fig. (8)] as well as its mass moments of inertia were calculated using the commercial code Prodas.

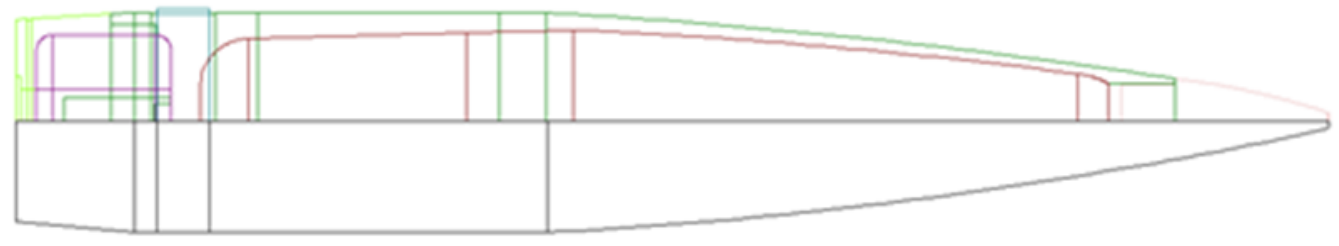

\section{Fig. 8 Elements of projectile K307 to calculate Clp and mass moments of inertia by Prodas.}

Figure 9 shows the comparison of time history of spin rate calculated by the model using $C_{l p}$ and the corresponding output of Prodas in case of muzzle velocity of $910 \mathrm{~m} / \mathrm{s}$ and initial angle of fire angle of 51.2o. Good agreement in general with maximum absolute error less than $4 \%$ at the transonic velocity regime.

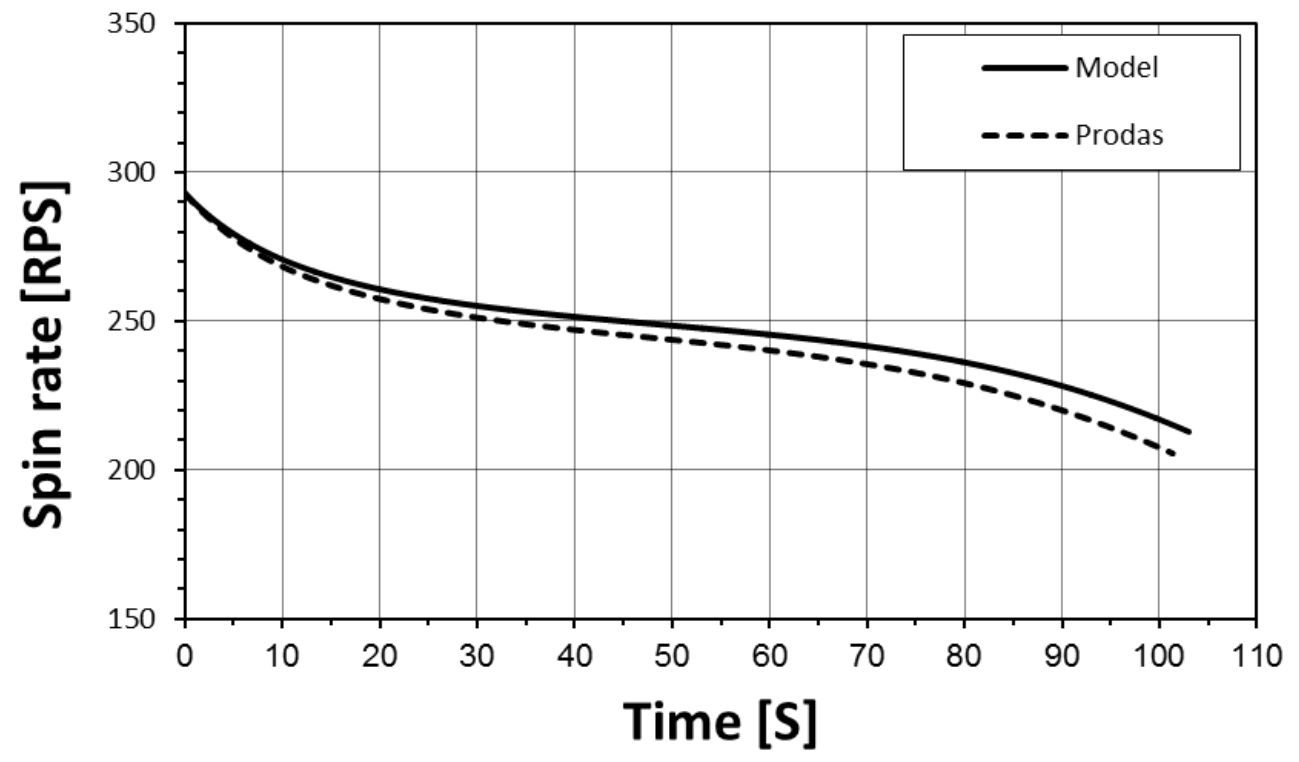

Fig. 9 Predicted history of spin rate at muzzle velocity $=910 \mathrm{~m} / \mathrm{s}$ and firing angle $=51.20$ compared with the predicted one using Prodas.

\section{Instantaneous burnt surface of base bleed grain}

Base bleed grain is considered the gas generator that may take different shapes such as tubular, slots, star, and wagon wheel. One of the most famous configurations is tubular with slots grain. This configuration is used in the current study since it is applied to both M864, K307 155mm projectiles. The gas generator consists of two identical solid propellant grains as shown in Fig. 1. These two elements provide an inner cylindrical burning surface and four planer surfaces separated by a $3 \mathrm{~mm}$ slot. The slots are held open during launch by four spacers. In these calculations the regression rates on the cylindrical surface and on the slot surfaces are assumed uniform over the surfaces but not necessarily the same [3,11]. Burning is only permitted on the inner cylindrical surface and the 4 slots. Other surfaces of the grain are covered by inhibitor. As shown in Fig. 1 base bleed grain surface area is split into two main surface areas, cylindrical surface and slot surface which were split into many areas as 
shown in Fig. 10. Area calculation during burn time is performed according to the following equations [3]:
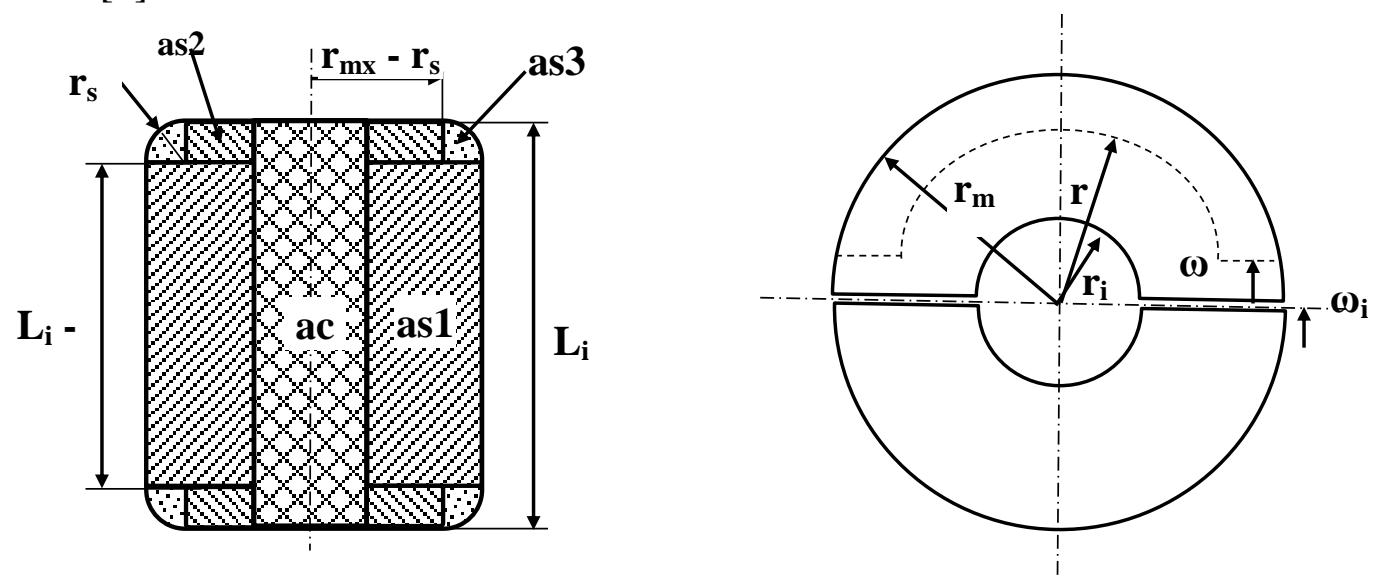

Fig. 10 Base bleed grain geometry [3]

The radius change of the cylinder at any instant

$\Delta \mathrm{r}=\mathrm{U}_{\mathrm{r}} \Delta \mathrm{t}$,

where

$\mathrm{U}_{\mathrm{r}}=\mathrm{k}_{\mathrm{c}} \mathrm{U}_{0} \mathrm{P}_{\mathrm{ch}}^{\alpha}$,

The radius, $\mathrm{r}$ at any increment time will be

$r=r_{i}+\Delta r$,

and the regression of the slot at any instant

$\Delta \omega=\mathrm{U}_{\omega} \Delta \mathrm{t}$

where

$\mathrm{U}_{\omega}=\mathrm{k}_{\omega} \mathrm{U}_{0} \mathrm{P}_{\mathrm{ch}}^{\alpha}$,

The slot, $\omega$ at any increment time will be

$\omega=\omega_{i}+\Delta \omega$,

Total grain surface area, $A_{b b}$

$\mathrm{A}_{\mathrm{bb}}=\mathrm{a}_{\mathrm{c}}+\mathrm{a}_{\mathrm{s}}$,

where

- Inner cylindrical surface area, $a_{c}$ :

$\mathrm{a}_{\mathrm{c}}=\left[2 \pi-2 \mathrm{n} \sin ^{-1}\left(\frac{\omega}{\mathrm{r}}\right)\right] \mathrm{rL}$,

and

- The slots surface area, $a_{s}$ were divided into three surfaces (Fig. 10) to include the change of grain length as result of the curved ends of the grain

$\mathrm{a}_{\mathrm{s}}=2 \mathrm{n \textrm {a } _ { \mathrm { s } 1 }}+4 \mathrm{n} \mathrm{a}_{\mathrm{s} 2}+4 \mathrm{na} \mathrm{a}_{\mathrm{s} 3}$,

- grain length, $L$ changes according to :

$\mathrm{L}=\mathrm{L}_{\mathrm{i}}-2\left[\mathrm{r}_{\mathrm{s}}-\sqrt{\left(\mathrm{r}_{\mathrm{s}}^{2}-\left(\mathrm{r}_{\mathrm{s}}-\mathrm{r}_{\mathrm{mx}}+\mathrm{r}\right)^{2}\right)}\right](1-\mathrm{j})$,

where

$\mathrm{a}_{\mathrm{s} 1}=\left(\mathrm{l}_{\mathrm{i}}-2 \mathrm{r}_{\mathrm{s}}\right)\left[\sqrt{\left(\mathrm{r}_{\mathrm{mx}}^{2}-\omega^{2}\right)}-\sqrt{\left(\mathrm{r}^{2}-\omega^{2}\right)}\right]$,

$a_{\mathrm{s} 2}=r_{\mathrm{s}}\left[\sqrt{\left(\mathrm{r}_{\mathrm{mx}}-\mathrm{r}_{\mathrm{s}}\right)^{2}-\omega^{2}}-\sqrt{\left(\mathrm{r}^{2}-\omega^{2}\right)}\right] \mathrm{j}$,

where 
$\mathrm{j}=1$ incase of $\mathrm{r} \leq\left(\mathrm{r}_{\mathrm{mx}}-\mathrm{r}_{\mathrm{s}}\right)$

and

$\mathrm{j}=0.0$ incase of $\mathrm{r}>\left(\mathrm{r}_{\mathrm{mx}}-\mathrm{r}_{\mathrm{s}}\right)$ then $\mathrm{a}_{\mathrm{s} 2}$ vanishes

$a_{\mathrm{s} 3}=\int \frac{\sqrt{\left(\mathrm{r}_{\mathrm{mx}}^{2}-\omega^{2}\right)}}{\sqrt{\left(\mathrm{r}^{\prime 2}-\omega^{2}\right)}}\left[r_{\mathrm{s}}^{2}-\left(\sqrt{\left(\mathrm{z}^{2}+\omega^{2}\right)}-r_{\mathrm{mx}}+\mathrm{r}_{\mathrm{s}}\right)^{2}\right]^{1 / 2} \mathrm{dz}$,

where this area is the contribution of the curved end corners of the grain and,

$r^{\prime}=r$ incase of $r \gg\left(r_{m x}-r_{s}\right)$,

$\mathrm{r}^{\prime}=\mathrm{r}_{\mathrm{mx}}-\mathrm{r}_{\mathrm{s}}$ incase of $\mathrm{r}<\left(\mathrm{r}_{\mathrm{mx}}-\mathrm{r}_{\mathrm{s}}\right)$,

Equation (27) is calculated using the trapezoidal rule.

The total mass flow rate of the surface area of base bleed is calculated:

$\dot{\mathrm{m}}_{\mathrm{N}}=\rho_{\mathrm{G}}\left[\mathrm{a}_{\mathrm{c}} \mathrm{U}_{\mathrm{r}}+\mathrm{a}_{\mathrm{s}} \mathrm{U}_{\omega}\right]$,

The end of base bleed grain burning occurs when $r=r_{m x}$ [3]

Figure 11 depicts different surface areas of base bleed grain of M864 projectile versus the inner radius. A good agreement can be noted between the calculated data and the published ones with maximum error less than $2 \%$ [3].

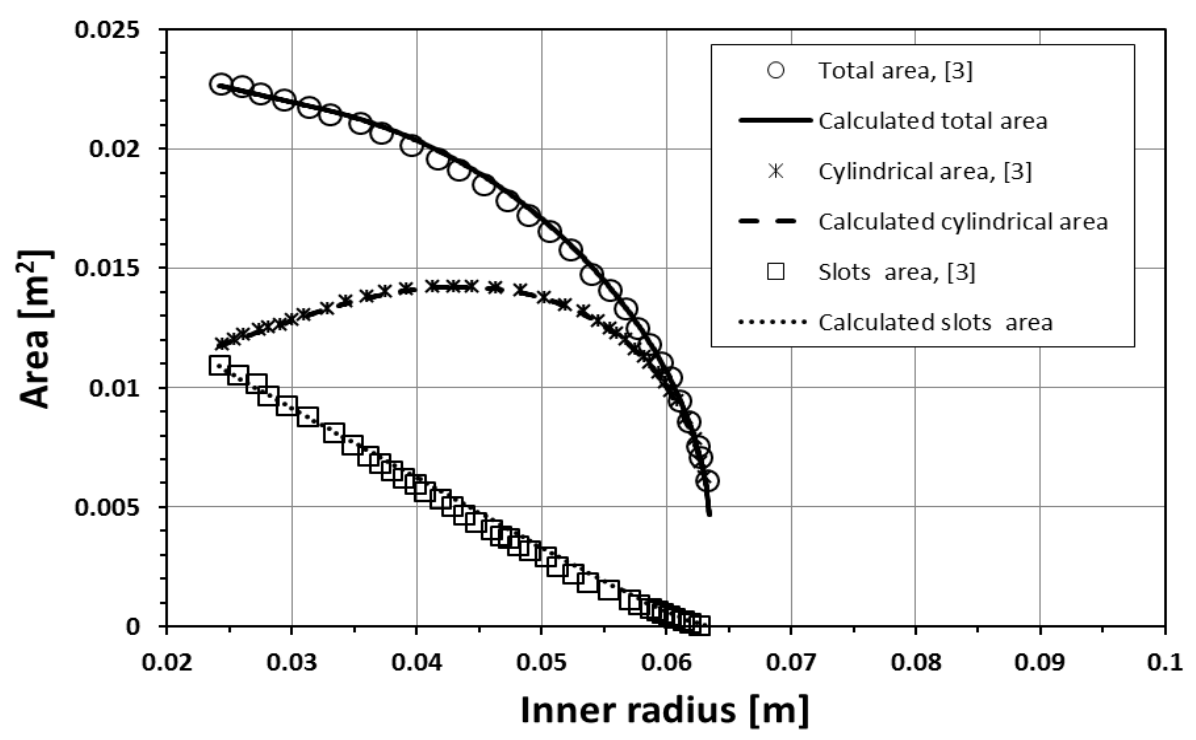

Fig. 11 Calculation of grain surfaces compared with their counterparts in Ref. [3] for the grain of M864 base bleed projectile

\section{Base bleed drag reduction}

The effect of drag reduction due to base bleeding $(\Delta \mathrm{CD})$ is added to the system of equations of motion by subtracting it from the total drag coefficient. Therefore the air resistance equation is written as follows:

$$
\mathrm{R}=\frac{1}{2} \rho_{\infty} \mathrm{v}^{2} \mathrm{~S}\left(\mathrm{C}_{\mathrm{D}_{0}}-\Delta \mathrm{C}_{\mathrm{D}}\right)(\mathrm{M}, \mathrm{Re})
$$

The total drag coefficient of base bleed projectile and its base drag coefficient can be written as the following equations:

$$
\mathrm{C}_{\mathrm{D} 0 \mathrm{~b}}=\mathrm{C}_{\mathrm{Do}}-\Delta \mathrm{C}_{\mathrm{Dbb}}
$$




$$
\mathrm{C}_{\mathrm{Dbb}}=\mathrm{C}_{\mathrm{Db}}-\Delta \mathrm{C}_{\mathrm{Dbb}}
$$

Drag reduction coefficient, $\Delta \mathrm{C}_{\mathrm{Dbb}}=\mathrm{f}\left(\mathrm{M}_{\infty}, \mathrm{I}, \mathrm{T}_{\mathrm{bb}}, \mathrm{a}_{\mathrm{G}}, \ldots\right)$ can be determined using the following equation $[18,20]$ :

$$
\Delta \mathrm{C}_{\mathrm{Dbb}}=\mathrm{C}_{\mathrm{Db}}\left(1-\mathrm{e}^{-\mathrm{IJ}}\right) \mathrm{C}_{\mathrm{k}}
$$

where, $\mathrm{J}$ is function of Mach number, i.e., $\mathrm{J}=\mathrm{f}(M)$ and its value is determined from firing tests and it has determined according to the procedures stated in Refs. $[18,20] . C_{k}$ takes different values according to the ratio between calculated injection parameter (I) and the optimum injection parameter $\mathrm{I}_{\mathrm{Lim}}$ as follows:

$$
\begin{gathered}
\mathrm{C}_{\mathrm{k}}=1.0 \quad \text { incase } \mathrm{I} \leq \mathrm{I}_{\mathrm{Lim}} \\
\mathrm{C}_{\mathrm{k}}=1-\left(\frac{\mathrm{I}}{\mathrm{I}_{\mathrm{Lim}}}-1\right)^{2} \mathrm{C}_{\mathrm{Lim}} \quad \text { incase } \mathrm{I}>\mathrm{I}_{\mathrm{Lim}}
\end{gathered}
$$

The constants $\mathrm{I}_{\mathrm{Lim}}, \mathrm{C}_{\mathrm{Lim}}$ are determined so that good agreement between calculations and firing data is achieved. Herein the drawn values of $\mathrm{I}_{\mathrm{Lim}}=0.005$ which coincides with the mentioned in [21] and for $\mathrm{C}_{\mathrm{Lim}}=0.25$.

The calculation of I according to equations $(1,2,3,17,20)$ requires the prediction of base bleed chamber pressure $(\mathrm{Pch})$ which is determined by the equality of mass flow rate of burning products through the orifice and mass flow rate of gases generated due to the grain burning. Mass flow rate of burning products through base bleed orifice is a function of the ratio between the projectile base pressure (Pd) during its flight and the base bleed chamber pressure. The value of this pressure ratio indicates if the base bleeding flow is subsonic or supersonic. Thus the condition of subsonic flow is:

$$
\frac{\mathrm{P}_{d}}{\mathrm{P}_{\mathrm{ch}}} \geq\left(\frac{2 \mathrm{k}}{\mathrm{k}+1}\right)^{\frac{\mathrm{k}}{\mathrm{k}-1}}
$$

Then the mass flux of burning products is given by

$$
\dot{\mathrm{m}}_{\mathrm{N}}=\rho_{\mathrm{G}} \mathrm{A}_{\mathrm{J}}\left(\frac{\mathrm{P}_{\mathrm{d}}}{\mathrm{P}_{\mathrm{ch}}}\right)^{1 / \mathrm{K}} \sqrt{\frac{2 \mathrm{~K}}{\mathrm{~K}-1} \mathrm{R}_{\mathrm{G}} \mathrm{T}_{\mathrm{G}}\left[1-\left(\frac{\mathrm{P}_{\mathrm{d}}}{\mathrm{P}_{\mathrm{ch}}}\right)^{\frac{\mathrm{K}-1}{\mathrm{~K}}}\right]}
$$

and, in case of supersonic flow:

where

$$
\begin{array}{r}
\frac{\mathrm{P}_{\mathrm{d}}}{\mathrm{P}_{\mathrm{ch}}}<\left(\frac{2}{\mathrm{k}+1}\right)^{\frac{\mathrm{k}}{\mathrm{K}-1}} \\
\dot{\mathrm{m}}_{N}=\frac{\gamma(\mathrm{K}) \mathrm{P}_{\mathrm{ch}} \mathrm{A}_{\mathrm{J}}}{\sqrt{\mathrm{R}_{\mathrm{G}} \mathrm{T}_{\mathrm{G}}}} \\
\gamma(\mathrm{K})=\sqrt{\mathrm{K}}\left(\frac{2}{\mathrm{~K}+1}\right)^{\frac{\mathrm{K}+1}{2(\mathrm{~K}-1)}}
\end{array}
$$

The projectile base pressure, $P_{d}$ is calculated by:

$$
\mathrm{P}_{\mathrm{d}}=\mathrm{P}_{\infty}\left(1-0.5 \mathrm{~K}_{\infty} \mathrm{M}^{2}\left(\frac{\mathrm{D}}{\mathrm{D}_{\mathrm{b}}}\right)^{2}\left(\mathrm{C}_{\mathrm{Db}}-\Delta \mathrm{C}_{\mathrm{Dbb}}\right)\right.
$$


It should be emphasized that occurring of supersonic flow in the orifice of base bleed is not recommended because base bleed jet will contain enough momentum to penetrate the wake and gets through the primary recirculation in behind projectile base leading to lowering base pressure resulting in decreasing of the drag reduction [19]. Thus optimum injection parameter for base bleeding is of a value located in the shaded area in Fig. 12 which displays the relation between the projectile base pressure and the injection parameter [22].

For the calculations of drag reduction, an initial value of Pch is proposed, and then introduced in the calculations of base bleed grain burn rate according to equations (17, 20). Mass flow rate is calculated according to equation (33b) (34a), or recalculated new Pch according to equation (33b) or (34a). Absolute error between initial and new Pch is calculated and the iteration is repeated until reaching acceptable error in Pch. Base drag is calculated and proceed to the next time step on trajectory. The base drag reduction is calculated until the moment of end of grain burning. At each time step during base bleed burning, projectile mass, $\mathrm{m}$ and its axial moment of inertia, $I_{X}$ is updated as follows [20]:

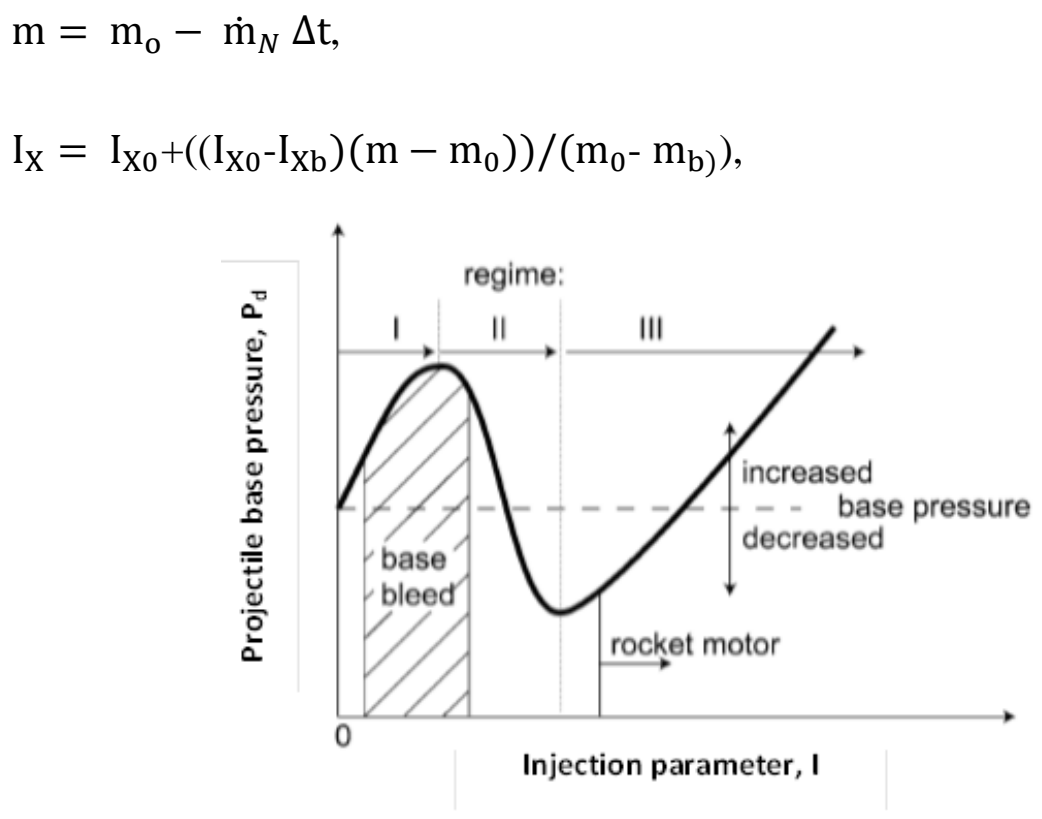

Fig. 12 Projectile base pressure versus injection parameter [22]

\section{Results and Discussions}

Figure 13 shows the comparison between calculated total drag coefficient versus Mach number for projectile K307 compared with experimental data obtained by firing [11] in case of initial velocity of $910 \mathrm{~m} / \mathrm{s}$ and angle of fire of 51.2o. It can be noted that there is a good agreement between the calculated and the measured data. It is thought that the difference between the calculated and measured data is due to neglecting the effect of igniter on the mass flow rate.

Figure 14 displays the trajectories of projectile provided with live base bleed compared with that one of projectile provided with inert base bleed unit. There is a good agreement between calculated trajectory of base bleed projectile and the measured data by firing with absolute error in range less than $1.5 \%$. The figure shows a substantial increase in range as result of base bleed with $30 \%$ when compared with the range with the same projectile provided with inert base bleed unit. 


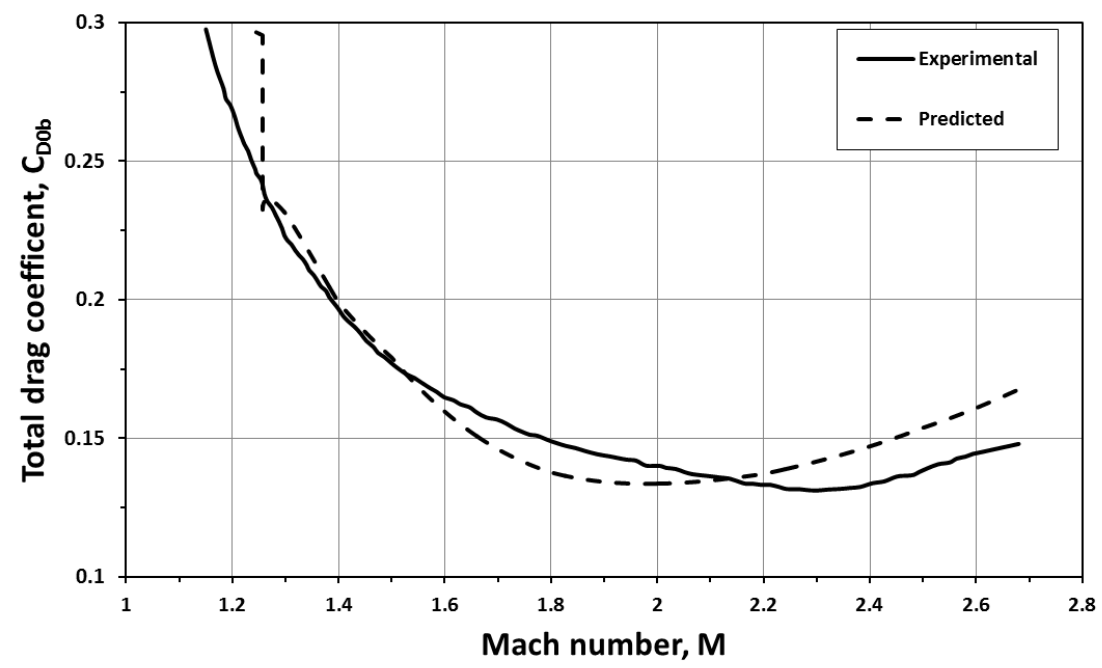

Fig. 13 Comparison of the predicted drag coefficient versus Mach number with the published data [11]

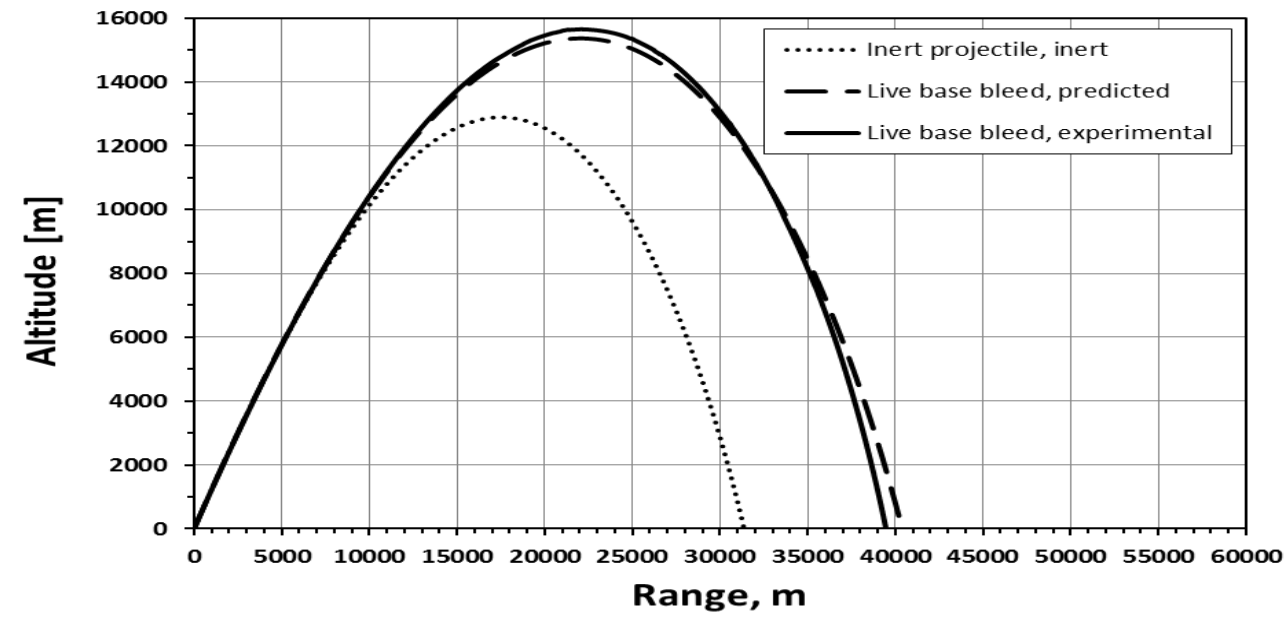

Fig. 14 Comparison between measured and predicted trajectories for live base bleed projectile with inert projectile at initial velocity of $910 \mathrm{~m} / \mathrm{s}$ and initial angle of fire of $51.2^{\circ}$

Figure 15 shows comparison of projectile altitude versus time of flight for live base bleed and inert projectile in case of initial velocity of $910 \mathrm{~m} / \mathrm{s}$ and angle of fire of $51.2 \mathrm{o}$. The time of flight of live base bleed projectile increased when compared with the flight time of inert projectile. Also live base bleed projectile goes for higher altitude as result of base bleed work.

Figure 16 shows comparison between the history of Mach number in case of live base bleed projectile (calculated and test fire) and the inert projectile. Good agreement is obvious except in the last seconds of projectile flight. It is thought that an error in tracking radar reading incurred at the first few seconds of projectile flight. The figure shows that the Mach number of live base bleed is always higher than the corresponding of inert projectile as a result of the benefits of base bleed unit. 


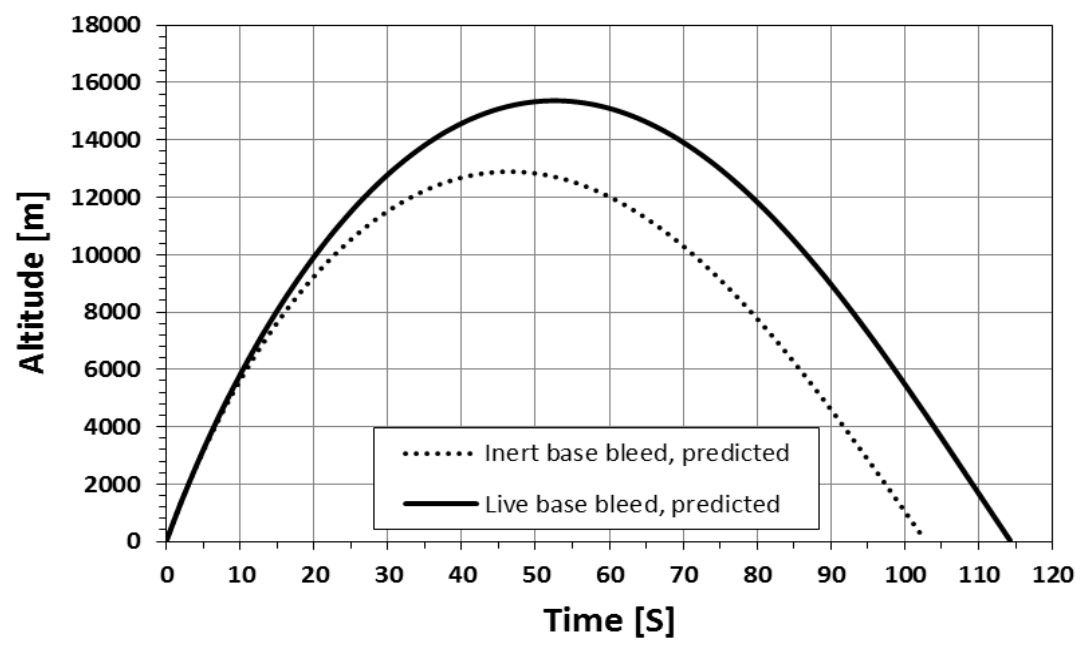

Fig. 15 Comparison of projectile altitude versus time of flight for live base bleed and inert projectile in case of initial velocity of $910 \mathrm{~m} / \mathrm{s}$ and angle of fire of $51.2^{\circ}$

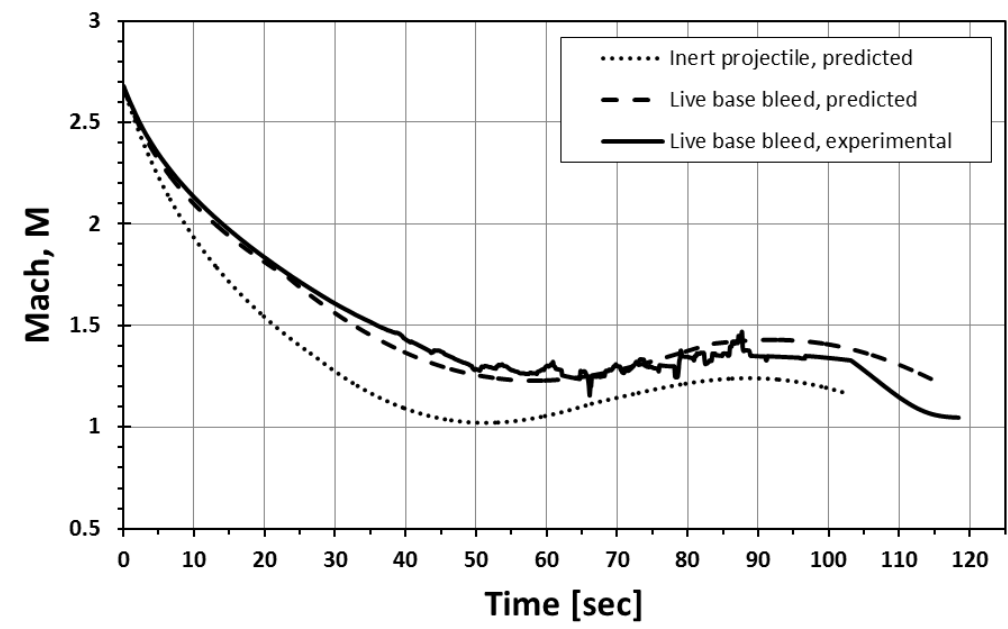

Fig. 16 Comparison of projectile Mach number versus time of flight for live base bleed and inert projectiles in case of initial velocity of $910 \mathrm{~m} / \mathrm{s}$ and angle of fire of $51.2^{\circ}$

Figure 17 shows the predicted change in the main dimensions of base bleed grain during time of burning. These dimensions are the grain length, the inner cylindrical radius and the slot distance. It can be concluded that base bleed burn time (which is here 51.2 seconds) is determined by the time of consumption of grain radius up to the outer radius $=60 \mathrm{~mm}$ not the slots and this coincides with [3,20]. Also, grain length remains constant until burning reaches a radius $=51.5 \mathrm{~mm}$ then the length decreases as result of taking into consideration in grain surface area calculations the effect of outer curvature of the base bleed grain (see Equ.(23a)) which is here $8.5 \mathrm{~mm}$.

Figure 18 shows the predicted change of the base bleed grain surface areas (total area, cylindrical area and area of the slots) with time. It can be seen that both total and the slots areas decrease with the progress of burring time. The rate of total area decreasing is less than the decreasing rate of the slots area resulting from the compensation of cylindrical area 
increase. Also at the beginning of grain burn, the contribution of the cylindrical surface area in the total area is nearly as the same as of slots area and with the progress of burn time, cylindrical area contribution increases and the opposite is true for slots.

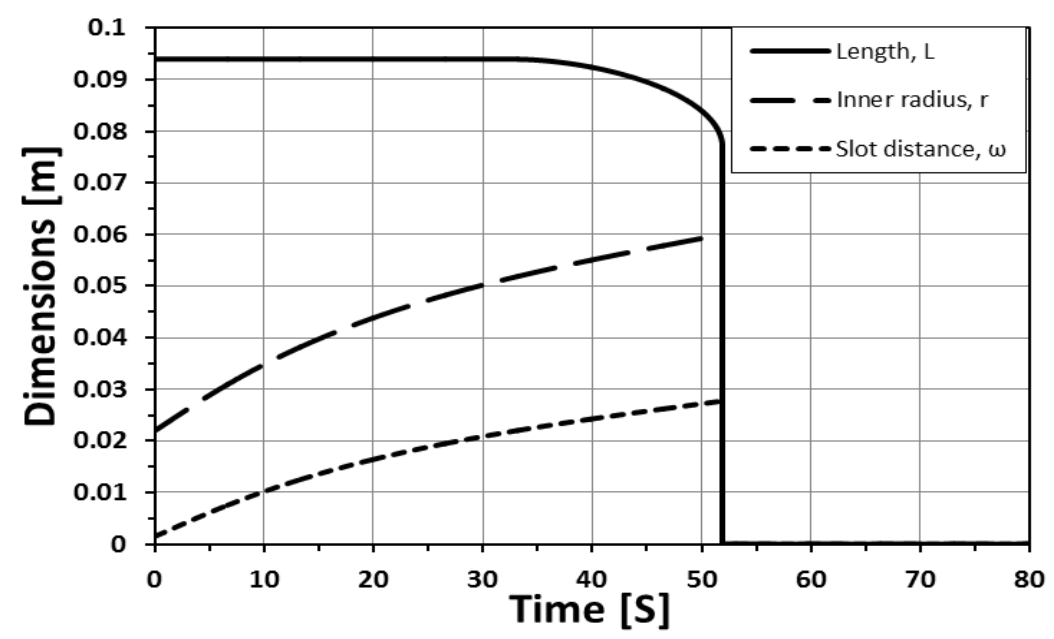

Fig. 17 Change in the main dimensions of base bleed grain with time of burning

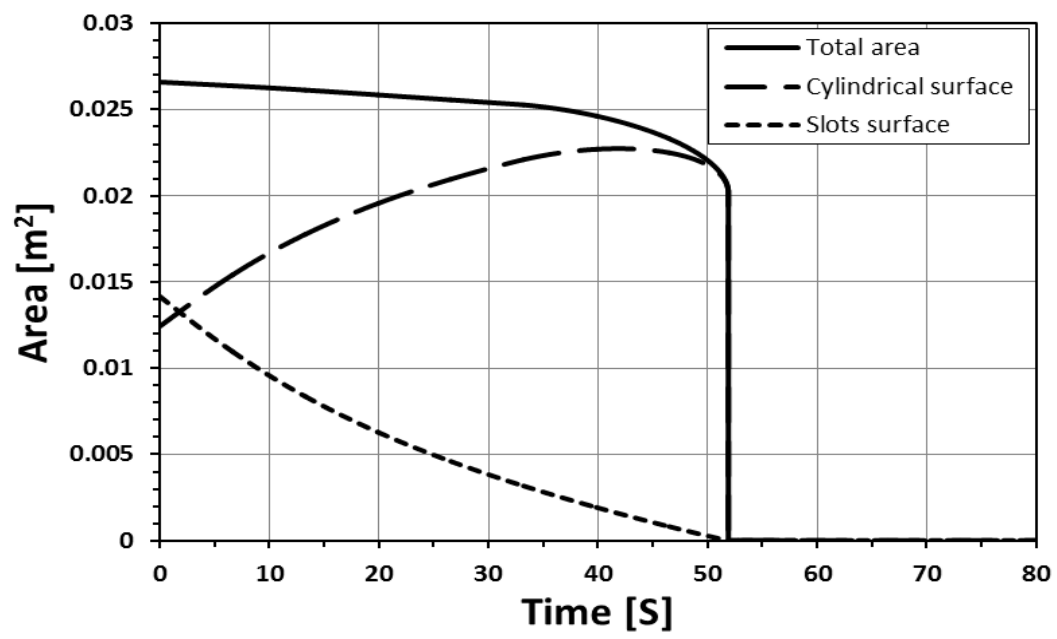

Fig. 18 Change of the base bleed grain surfaces area with time of burning

Figure 19 depicts the comparison of the calculated time histories of projectile base pressure $\mathrm{P}_{\mathrm{d}}$ and chamber pressure $\mathrm{P}_{c h}$, with free stream pressure, $\mathrm{P}_{\infty}$ in case of live base bleed projectile. The chamber pressure during the burn of base bleed grain is slightly higher than the base pressure by a value that guaranties the subsonic flow of gases. At the moment of the grain burn, the two pressure patterns coincide. Also it can be noted that the chamber pressure values proceed forward to the values of free stream pressure as the projectile gain more altitude and free stream pressure decreases unit the complete burn of base bleed. This is in agreement with the published data for M864 base bleed projectile for In-Flight Pressure Measurements [4]. 


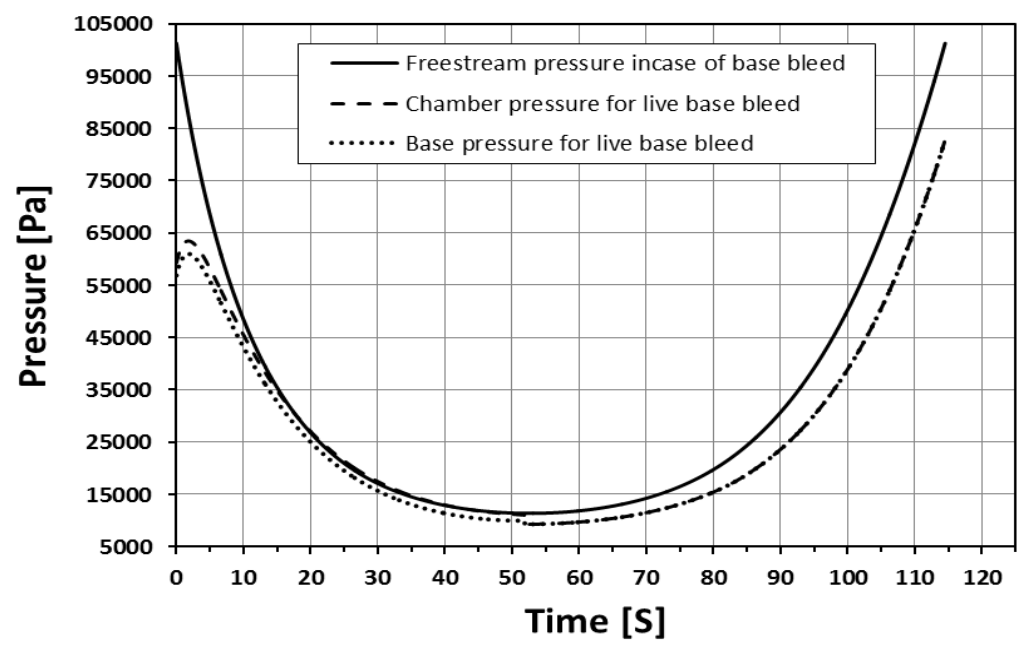
Fig. 19 Time change of chamber pressure and projectile base pressure
compared with free stream pressure in case of base bleed projectile

Figure 20 shows the predicted time history of mass flow rate and the ignition parameter. Mass flow rate decreases due to the decrease of the total surface area exposed for burning of the base bleed grain as shown in Fig.18. However mass flow rate decreases, injection parameter increases. This is as result of the continuous decrease of free stream flow rate $\dot{\mathrm{m}}_{\infty}$ (see Equs.1, 2) during the ascending part of projectile trajectory which lasts for 55 seconds while burn time is 51.2 seconds (see Fig.15, Fig. 17). The pattern of the mass flow rate coincides with the published $[5,24]$.

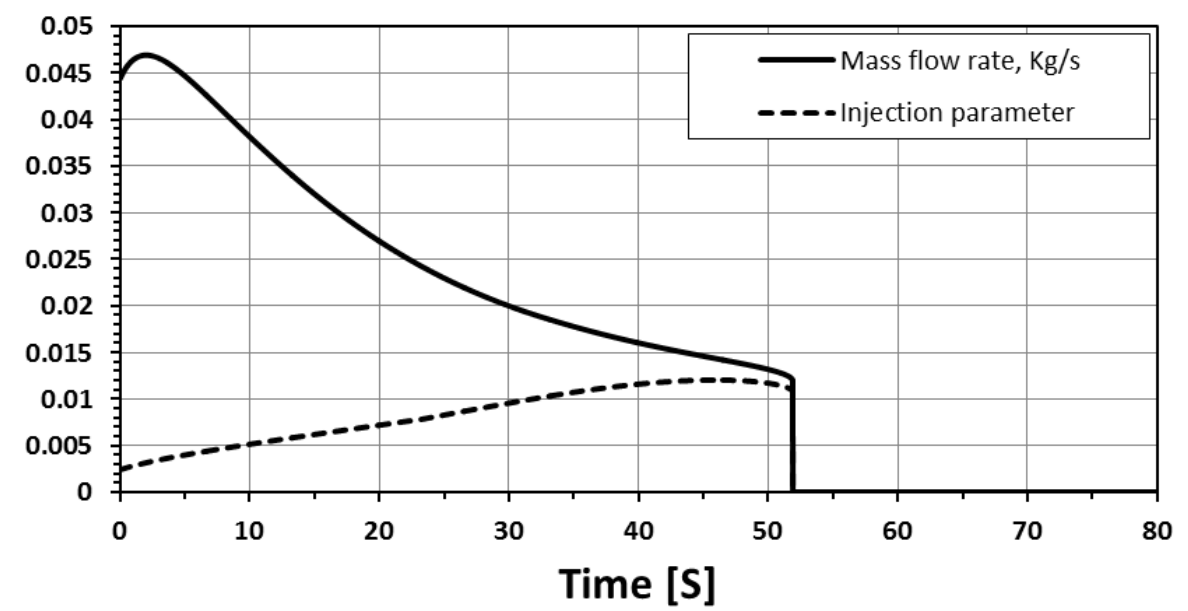

Fig. 20 Predicted time history of mass flow rate and the ignition parameter

Figure 21 displays a bar chart of the base bleed projectile range for different number of base bleed grain parts. As the number of grain parts increases the range increases. This coincides with $[11,20]$.

Figure 22 shows predicted time history of mass flow rate in case of different number of base bleed grain parts. With the increase of the number of grain parts, mass flow rate increases at the beginning of projectile flight then it decreases. The range increases since the mass flow rate is relatively high at the first seconds of projectile travel resulting in higher base drag reduction. Injection parameter has a similar pattern as shown in Fig. 23. 


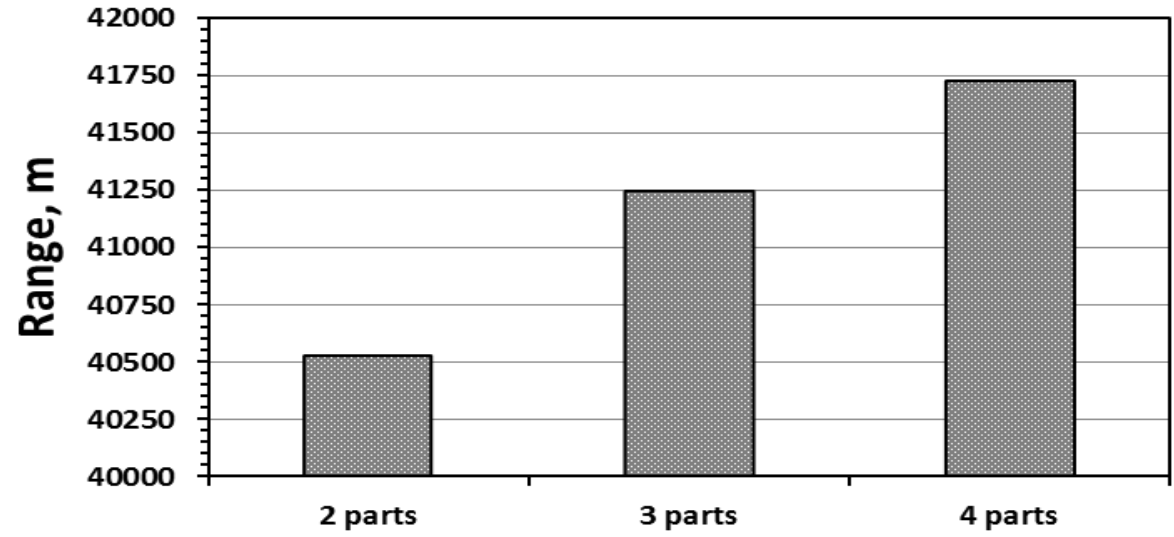

No. of base bleed grain parts

Fig. 21. Predicted maximum range in case of different number of base bleed grain parts

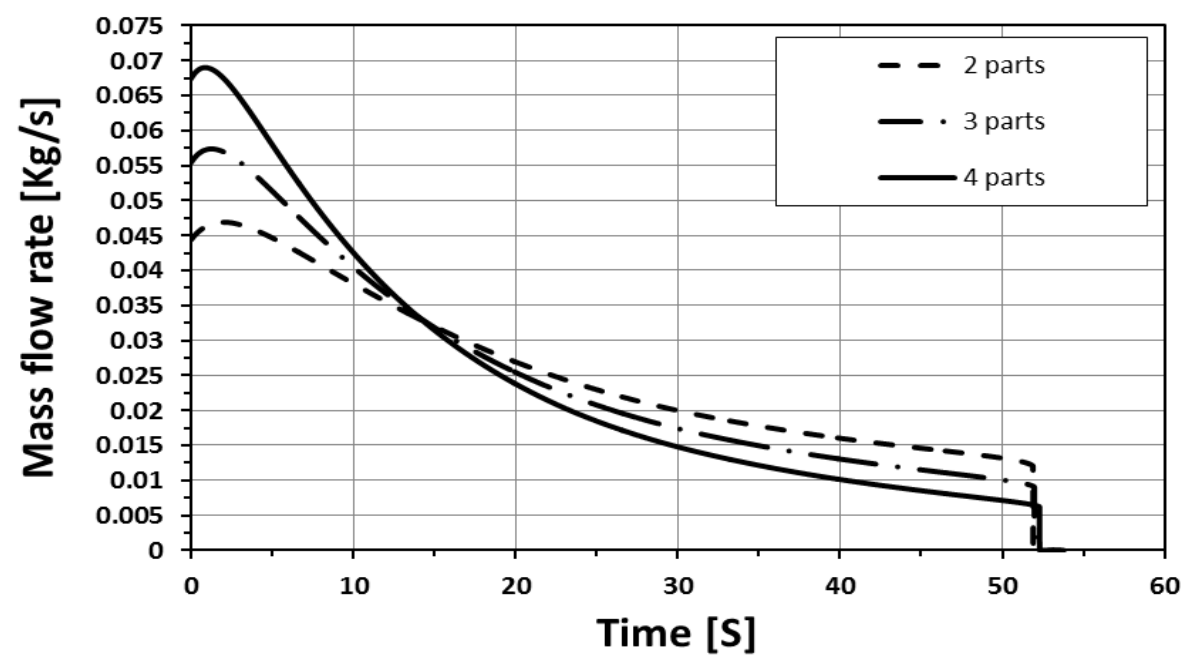

Fig. 22 Predicted time history of mass flow rate in case of different numbers of base bleed grain parts

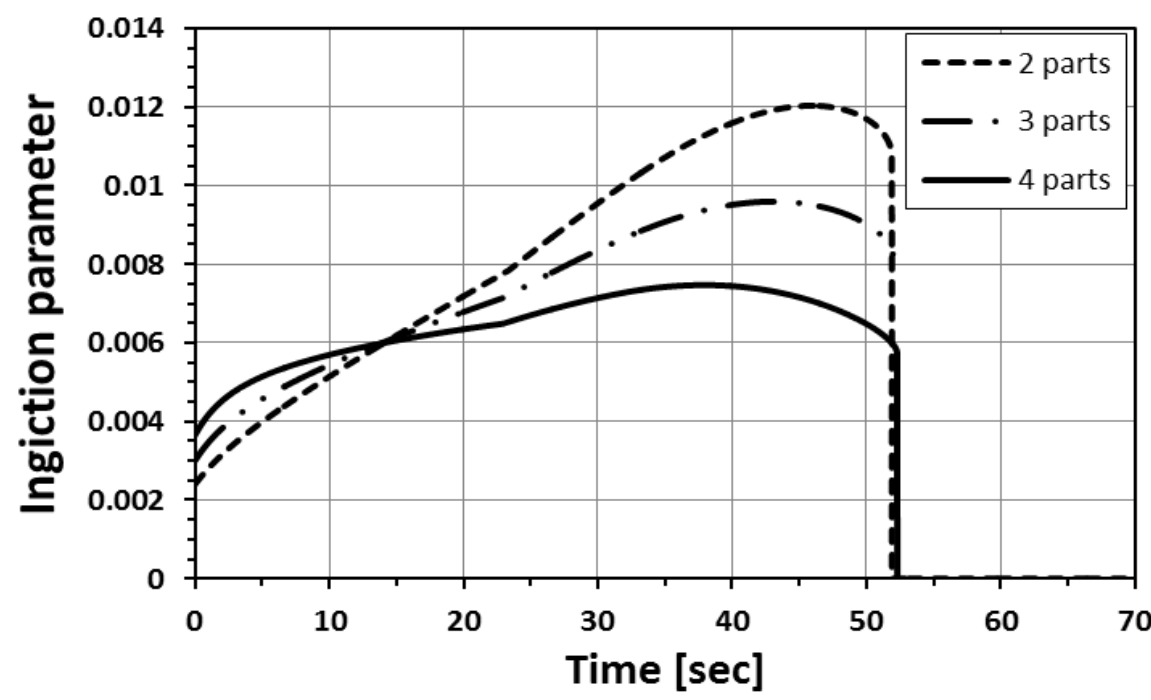

Fig. 23 Predicted time history of injection parameter in case of different number of base bleed grain parts 
The explanation of changing the mass flow rate in case of increasing grain parts can be realized from the instantaneous burnt surfaces displayed in Fig. 24 that shows for all cases, total and slot areas decrease while cylindrical area increases with time. With the increase of grain parts $\mathrm{n}$, the values of cylindrical area decrease (see Eq. 23) while the values of slot area increase (see Eq. 24). As a result of that, the total area is higher at the beginning up to certain inflation point after which total area decreases. This pattern affects the pattern of both mass flow rate and injection parameter as shown previously.

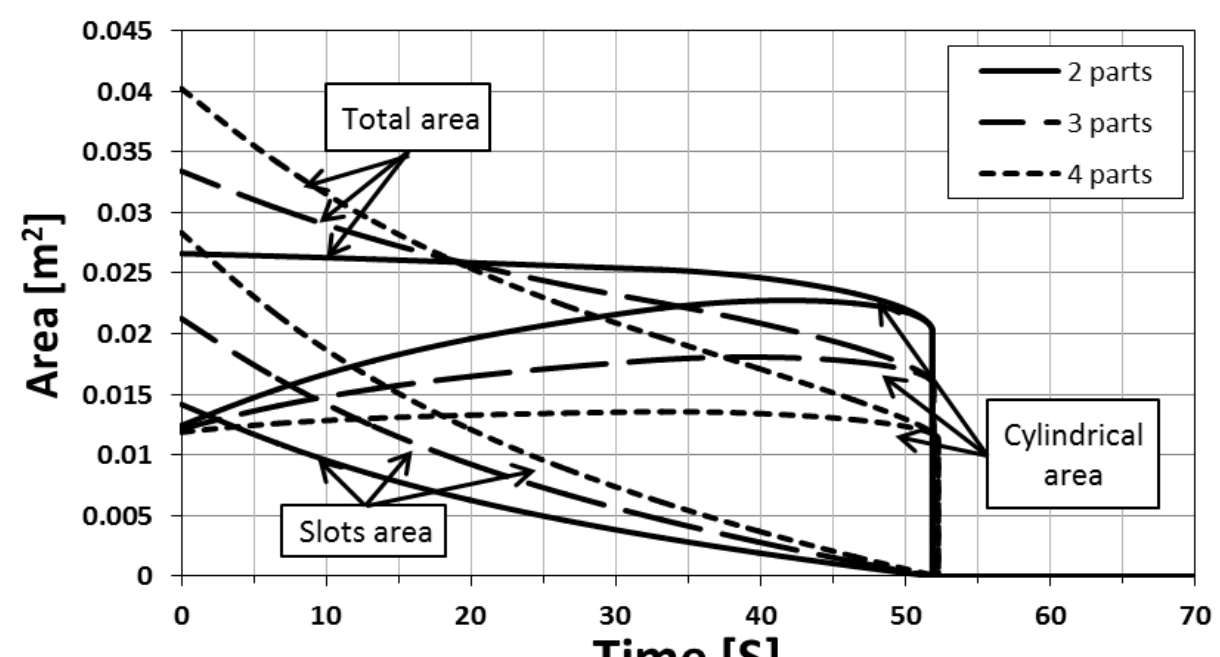

Time [S]

Fig. 24 Predicted time history of base bleed grain surfaces area in case of different number of base bleed grain parts

Figure 25 shows the predicted maximum range for different burn rate keeping pressure exponent $(\alpha)$ the same. There is an optimum burn rate that ranges from 1.1 to $1.3 \mathrm{~mm} / \mathrm{s}$. Off this values, maximum range decrease specially with higher burn rate. For optimum burn rates, base bleed grain provides adequate mass flow rate to reduce drag and also does not consumed in short time allowing the burn time to extend nearly half the flight time of projectile [11]. This is obvious in Fig. 26 that shows predicted time histories for injection parameter for different burn rate. Increasing burn rate, increases injection parameter and decreases burn time of base bleed grain.

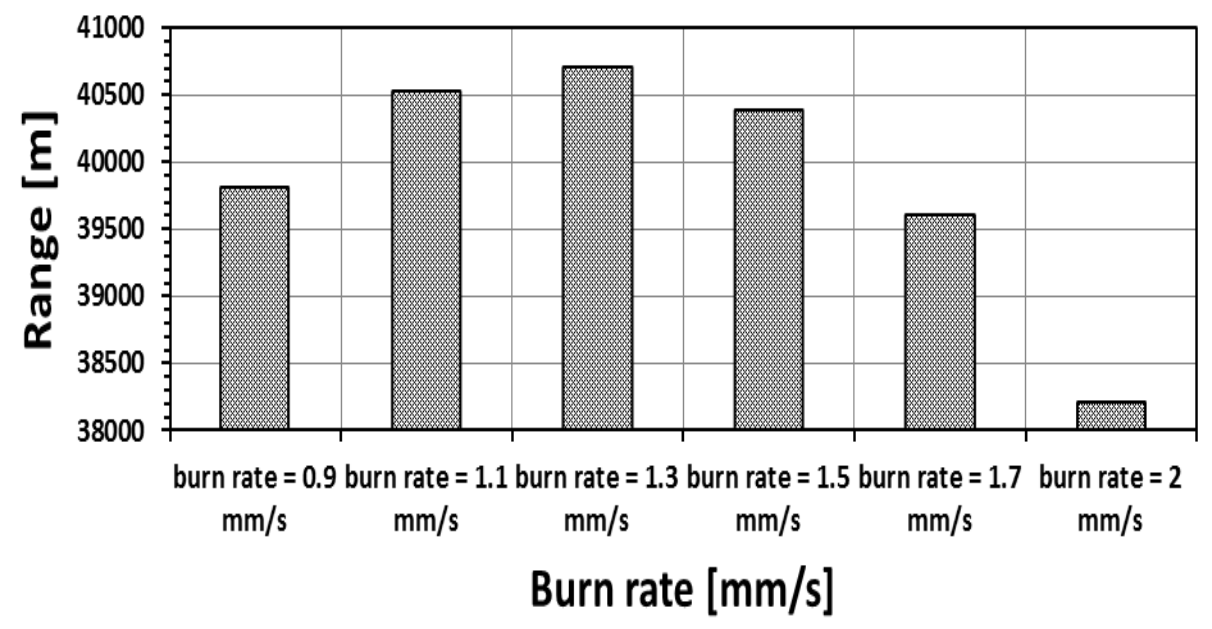

Fig. 25 Predicted time history of base bleed grain surfaces area in case of different number of base bleed grain parts 


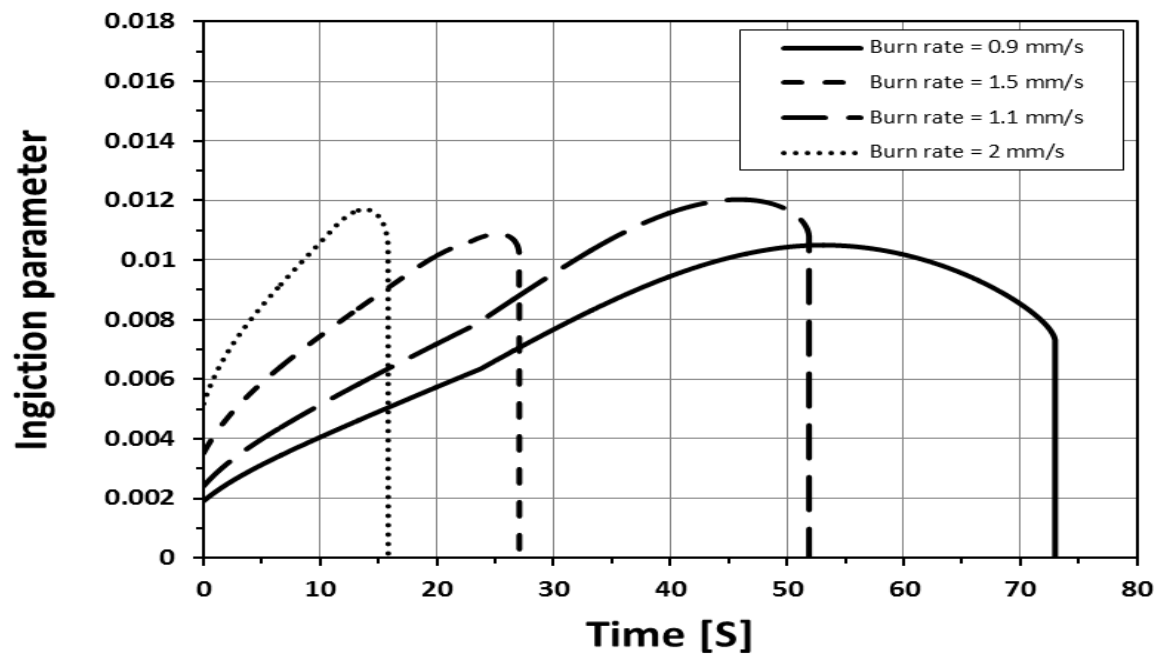

Fig. 26 Predicted time history of injection parameter for different burn rates.

It can be concluded from the above mentioned that, it is more efficient when; (1) base bleed grain may provide higher mass flow rate at the first period of projectile flight to gain maximum drag reduction at this high supersonic Mach number region as mentioned in [24] and (2) when base bleed burns for long time up to nearly half of projectile time of flight [11]. To demonstrate the important of drag reduction during the initial period of projectile flight, the model was modified to start base bleed grain burn after certain delay time of projectile exit from the muzzle. Fig. 27 shows the relation between projectile range and base bleed burn delay time. It can be seen, range decreases with the increase of delay time. In case of delay time $=8$ seconds, range decreased about $10 \%$ even though base bleed grain burn time increases with the increase of delay time as it can be seen in Fig.28.

The increase in burn time is expected because with longer delay time, base bleed grain will burn into higher altitudes with lower range of atmospheric pressures leading to lower burn rate for base bleed grain. In reality, delay time may last up to 1.5 seconds [25] and it will badly affect dispersion and range

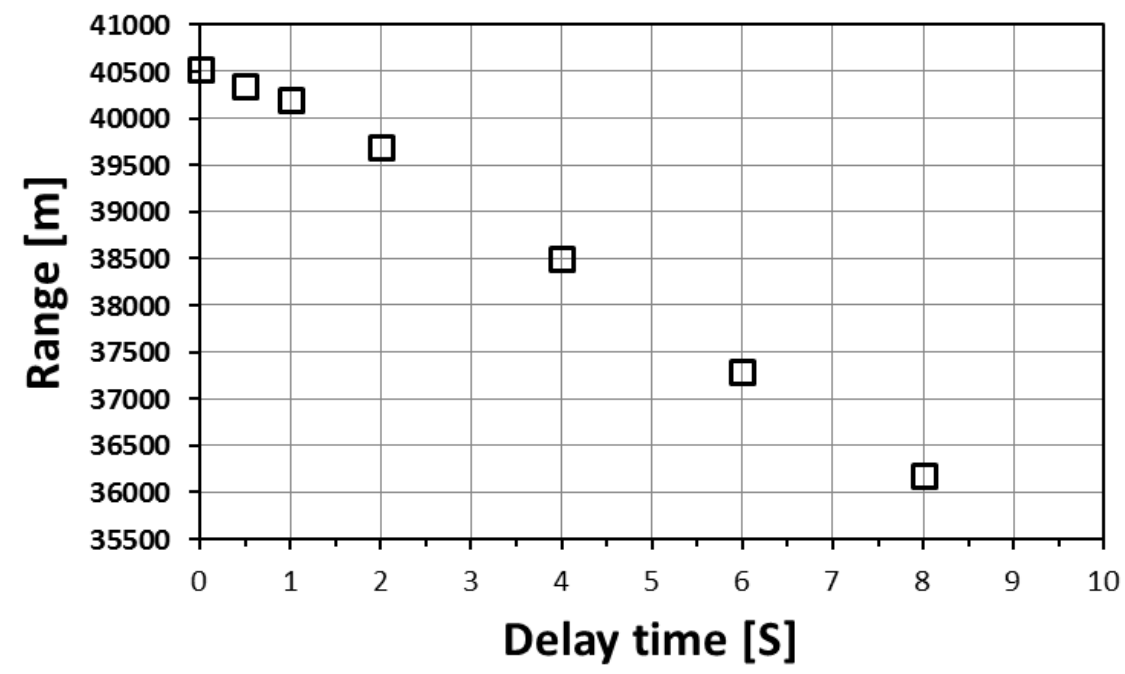

Fig. 27 Projectile range versus delay time. 


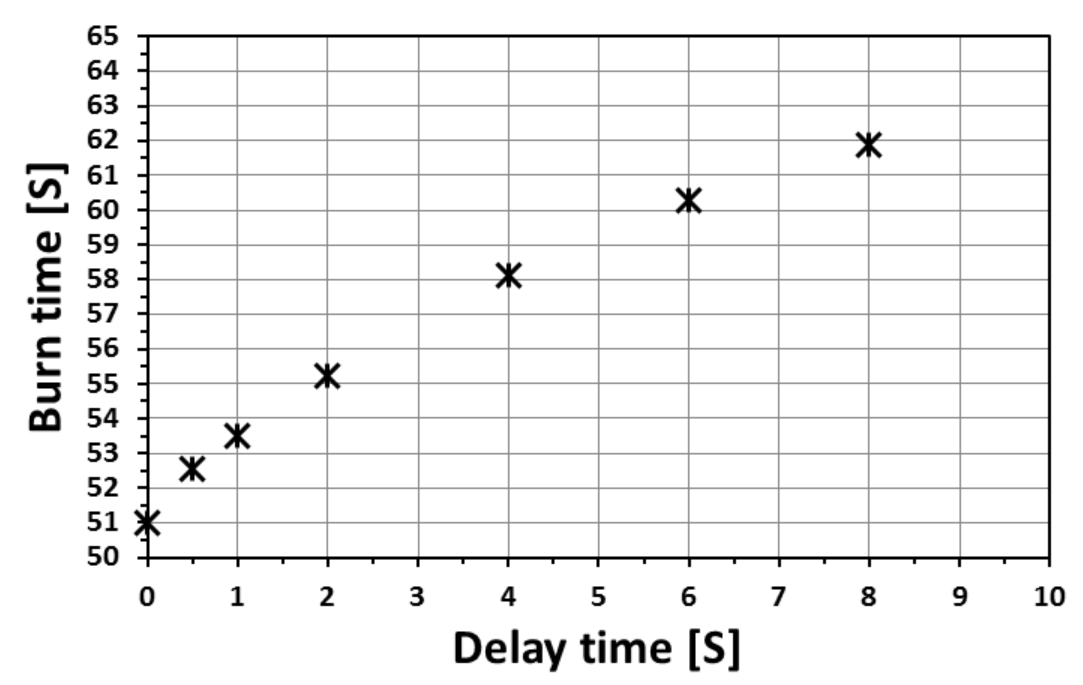

Fig. 28 Base bleed grain burn time versus delay time.

To achieve these goals, it is suggested that a new technique to manipulate the pattern of mass flow rate, by splitting base bleed grain length in to 2 parts, one part (part A) with higher burn rate while the other (part $B$ ) has the original burn rate (multi-burn rate grain). All main dimensions of base bleed grain (part $\mathrm{A}+$ part $\mathrm{B}$ ) is as the same as original grain.

Figure 29 shows predicted maximum range in case of multi-burn rate grain. Part A with length $=30 \mathrm{~mm}$ and different burn rates $(2.1,2,1.8) \mathrm{mm} / \mathrm{s}$. The length chosen here is just to demonstrate the concept. Also the figure included the range in case of original base bleed grain. For multi-burn rate grain maximum range is higher than the range of original grain also by increasing burn rate of part A, the maximum range increases. In Fig. 30 the patterns of mass flow rate in the previously mentioned trails show that, for multi-burn rate mass flow rate is higher compared with mass flow rate in case of original grain till the time of consumption of part A. after this point the mass flow rate is lower than in case of original grain because grain surface area after the burn out of part A is less than in case of original grain. Even though the ranges for multi-burn grain is higher because it provided more mass flow rate in projectile supersonic regime leading to more reduction in drag. The higher is the burn rate for part A, the shorter is the time of its burn.

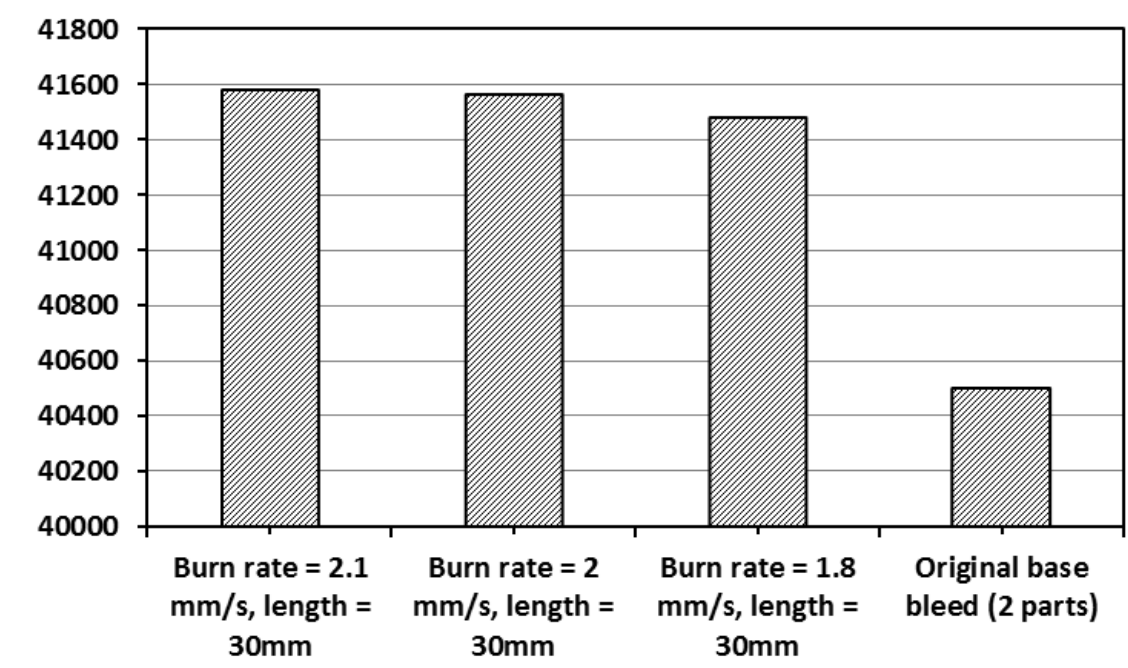

Fig. 29 Predicted maximum range in case of multi-burn rate grain for different burn rates compared with original base bleed grain 


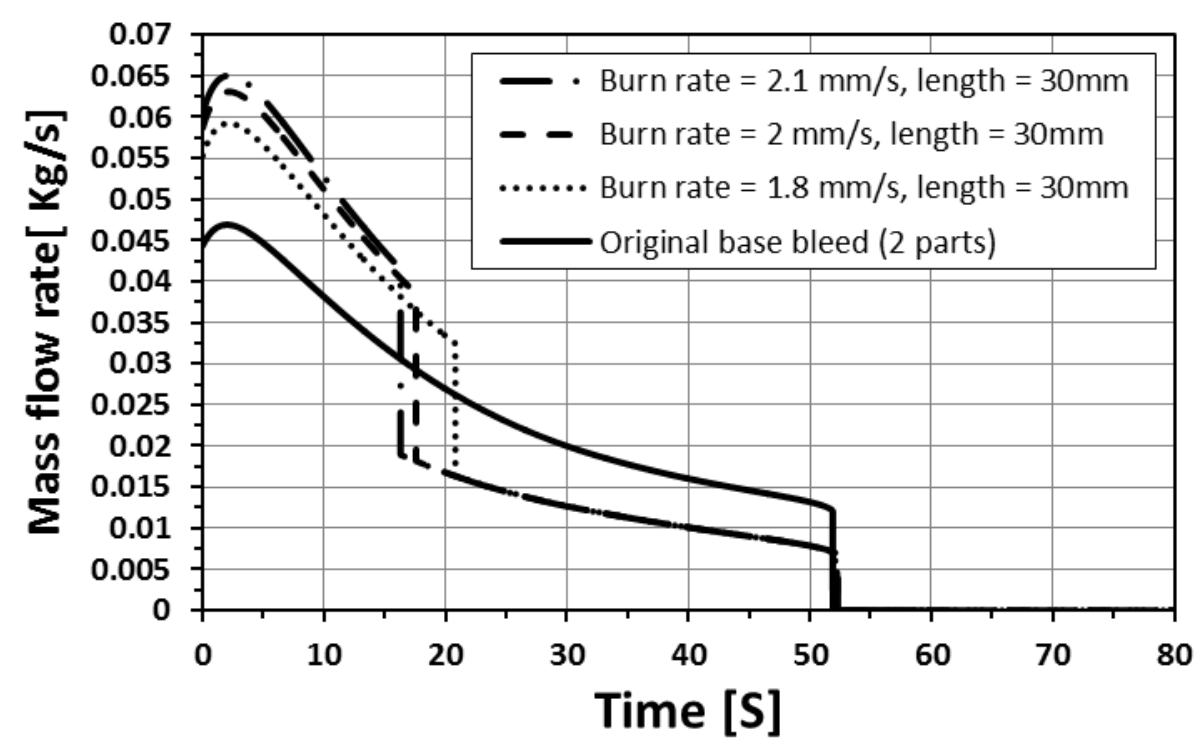

Fig. 30 Predicted mass flow rate in case of multi-burn rate grain for different burn rates compared with original base bleed grain

\section{Conclusion}

Effect of base bleed unit has been studied using CFD computational resources and the commercial code PRODAS to simulate the trajectory in case of the base bleed unit is switched on or off. The effect of change base bleed grain main dimensions has been investigated.

It has been found that the k-omega SST turbulence model is the proper one among used turbulence models since it gives the nearest results compared with experimental ones.

It has been concluded that base bleed unit becomes more efficient when its mass flow rate is relatively large during the first few seconds of projectile flight. This can be achieved by increasing grain parts or the new introduced technique by having multi-burn rate grain.

\section{References}

[1] Nils-Erik, Kurt Andersson and Yhgve Nilson "Testing of Parts and Complete Units of the Swedish Base Bleed System", First International Symposium on Special Topics in Chemical Propulsion, Athens, Greece, 23-25 November (1988).

[2] Nils Hubberud and Ivar J. Ye, "Extended Range of $155 \mathrm{~mm}$ Projectile Using an Improved Base Bleed Unit. Simulation and Evaluation", 26th Int. Sympo. on Ballistics, Florida, USA, 12-16 September (2011).

[3] J. Danbergand, "Analysis of the Flight Performance of the $155 \mathrm{~mm}$ M864 Base Burn Projectile", Technical Report BRL-TR-3083, US Army Ballistic Research Laboratory, (1990).

[4] Lyle D. Kayser, John D. Kuzan and David N. Vazquez, "In-Flight Pressure Measurements on Several 155mm, M864 Base Burn Projectiles", AD-A232 225, US Army Ballistic Research Laboratory, (1991).

[5] Nils E. Gurnners, K. Andersson and R. Hellgren, "Base-Bleed Systems for Gun Projectiles", aeronautics and astronautics progress, Vol. 16, No. 1, pp. 537-561 (1987).

[6] Xifu. Guo, "Discussion for two important parameters of base bleed projectile", First International Symposium on Special Topics in Chemical Propulsion, Athens, Greece, 23-25 November (1988). 
[7] J. Danbergand C. Nietudicz, "Predicted Flight Performance of Base Bleed Projectile", 26th joint propulsion conference, Florida, USA, 16-18 July (1990), (AIAA 90-2069).

[8] Jan-Kaung Fu and Shen-Min Liangt," Drag Reduction for Turbulent Flow over a Projectile: Part I " Journal of Spacecraft and Rockets, Vol. 31,No. 1: pp. 85-92. (1994).

[9] Tarun Mathur and J. Craig Button, "Base-Bleed Experiments with a Cylindrical Afterbody in Supersonic Flow" Journal of Spacecraft and Rockets, Vol. 33, No. 1 : pp. 30-37. (1996).

[10] Young-Ki Lee, Heuy-Dong Kim and S. Raghunathan, "Optimization of Mass Bleed for Base-Drag Reduction" AIAA Journal, Vol. 45, No. 7 : pp. 1472-1477. (2007).

[11] Jun-Silk Hwang and Chang-Kee Kim, "Structure and Ballistic Properties of K307 Base Bleed Projectile", 16th Int. Sympo. on Ballistics, California, USA, 23-27 September (1996).

[12] V. Schabort and P.A. Karsten, "Toward A Better Base-Bleed", 18th Int. Sympo. on Ballistics, Texas, USA, 15-19 November (1999).

[13] Z. Ling-Ke, Z. Yan-Huang, Y. Yong-Gang and Z. Wei, "Studying on Firing Range of Base Bleed Projectile Caused by Inconsistent Base Bleed Unit Working", 25th Int. Sympo. on Ballistics, Beijing, China, 17-21 May (2010).

[14] A. Ibrahim and A. Filippone, "Effect of Porosity Strength on Drag Reduction of a Transonic Projectile", Journal of Aircraft, Vol. 44, No. 1, : pp. 310-316. (2007)

[15] James DeSpirito and Karen R. Heavey,"CFD Computation of Magnus Moment and Roll Damping Moment of a Spinning Projectile", AIAA Atmospheric Flight Mechanics Conference and Exhibit, Rhode Island, USA, 16 - 19 August (2004).

[16] Sriram Doraiswamy and Graham V. Candler, "Detached Eddy Simulations and Reynolds-Averaged Navier-Stokes Calculations of a Spinning Projectile", Journal of Spacecraft and Rockets, Vol. 45, No. 5, : pp. 935-945. (2008).

[17] James DeSpirito and Peter Plostins, "CFD Prediction of M910 Projectile Aerodynamics: Unsteady Wake Effect on Magnus Moment", AIAA Atmospheric Flight Mechanics Conference and Exhibit, South Carolina, USA, 20 - 23 August (2007).

[18] A.Z. Ibrahim, "Ballistic Performance of Base Bleed Unit" (Master's Degree Thesis, MTC, (2000).

[19] Prodas user manual

[20] Slobodan jaramaz and milojko injac, "Effect of grain characteristics on rangeof artillary projectiles with base bleed", First International Symposium on Special Topics in Chemical Propulsion, Athens, Greece, 23-25 November (1988).

[21] Alain Davenas, "Solid Rocket Propulsion Technology", pergamon Press Ltd., England, (1993).

[22] H. Bournot, E. Daniel and R. Cayzac, "Improvements of the base bleed effect using reactive particles", International Journal of Thermal Sciences, 45,: pp. 1052-1065. (2006).

[23] Robert F. Lieske and Dr. James E. Danbergt, "Modified Point Mass Trajectory Simulation for Base-Burn Projectiles", Astrodynamics Conference, USA, 1992, (AIAA92-4641).

[24] Kurt Andersson, "different means to reach long range $>65 \mathrm{Km}$, for future $155 \mathrm{~mm}$ artillery systems. Possibilities and limitation", 17th Int. Sympo. on Ballistics, Midrand, South Africa, 23-27 March (1998).

[25] L. D. Kayser, J. D. Kuzan, and D. N. Vazquez, "Flight testing for a $155 \mathrm{~mm}$ base burn projectile", AD-A222 562, US Army Ballistic Research Laboratory, (1990). 